\title{
Los conglomerados sintectónicos de la Formación Las Cumbres (Plio-Pleistoceno), Sierras Pampeanas de La Rioja y Catamarca, Argentina
}

\author{
Gerardo E. Bossi ${ }^{1}$, Sergio M. Georgieff ${ }^{1}$, Claudia M. Muruaga ${ }^{2}$, Lucía M. Ibáñez ${ }^{3}$, Javier G. Sanagua ${ }^{4}$
}

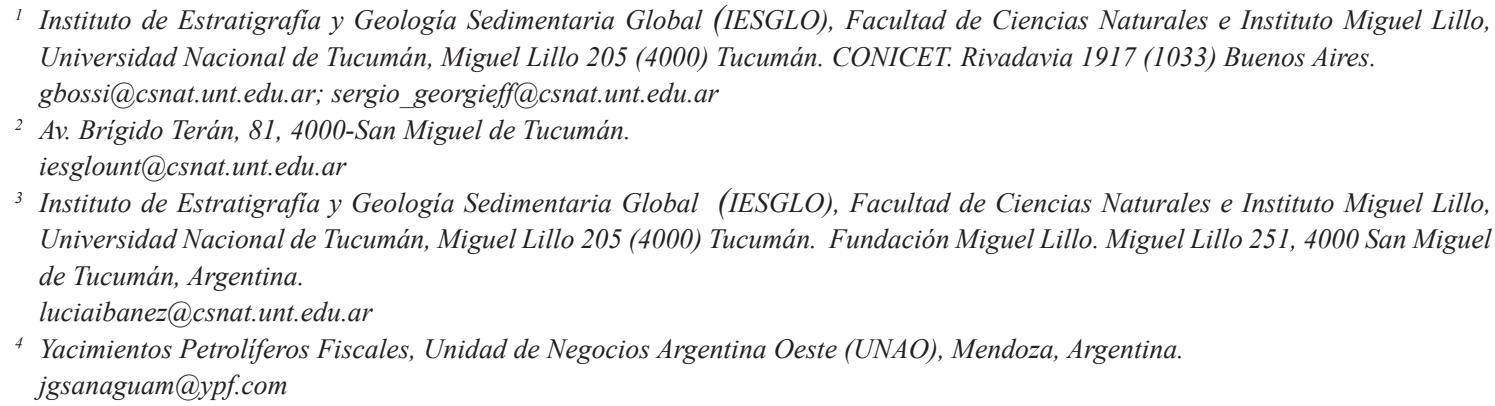

\begin{abstract}
RESUMEN. La Formación Las Cumbres (Plio-Pleistoceno) aflora extensamente en el área comprendida entre las sierras de Velasco y Paimán al sur y las sierras de Vinquis y Zapata al norte (Provincias de Catamarca y La Rioja, NO Argentina) cubriendo concordantemente la Formación Salicas (Mioceno tardío-Plioceno temprano). La Formación Las Cumbres es una sucesión granocreciente de conglomerados y areniscas que desarrollan una gran bajada aluvial formada durante el pico del levantamiento de las Sierras Pampeanas. En el sector sureste del área estudiada (las Cumbres de los Pozuelos), la falla transpresiva Uscamayo creó cuatro alounidades locales separadas por discordancias angulares (progresivas), en el bloque hundido. Cada alounidad constituye un estadio de actividad tectónica intensa, mientras que las discordancias representan etapas intermedias de intensa erosión y pedimentación. Se han distinguido dos facies sedimentarias principales: 1. conglomerados de milonitas angulosas y granitos deformados que dominan la parte sur del sistema de dispersión y 2. conglomerados polimícticos redondeados (granitos, esquistos, volcanitas, metavolcanitas y milonitas) que corresponden al sector norte. Las facies 1 provienen de las sierras de Velasco, cerro La Punta y Paimán, mientras que las facies 2 derivan del conjunto de sierras integradas por Vinquis, Zapata, Copacabana y Cerro Negro. Los dos sistemas convergen hacia el área de las Cumbres de los Pozuelos para hundirse allí en el 'Bolsón de Pipanaco'. Estos sistemas de dispersión no son congruentes con la posición actual de las sierras que han sufrido desplazamientos importantes en sentido norte-sur durante la etapa más intensa de levantamiento, ocurrida en el Pleistoceno temprano y 'medio'.
\end{abstract}

Palabras claves: Sierras Pampeanas, Conglomerados neógenos, Sistemas de dispersión, Discordancias angulares sinsedimentarias. 


\begin{abstract}
Syntectonic conglomerates of the Las Cumbres Formation (Plio-Pleistocene), Pampean Ranges from La Rioja and Catamarca, Argentina. The Las Cumbres Formation (Plio-Pleistocene) crops out extensively between the Zapata -Vinquis Ranges to the north and the Paimán-Velasco Ranges to the south (La Rioja and Catamarca Provinces, NW-Argentina) conformably overlying the Salicas Formation of late Miocene-early Pliocene age. The Las Cumbres Formation is a coarsening-upwards succession of conglomerates and sandstones related to a huge alluvial bajada. In the southeastern part of the mapped area, the Uscamayo transpressive fault created four local allounits separated by angular unconformities developed along the southern down-thrown block (the Cumbres de los Pozuelos). Each unconformity defines a stage of the Uscamayo fault activity followed by an intense reworking and pedimentation of the up-thrown northern block and sedimentation and differential subsidence of the southern block. At the western flank of the Velasco Range the Las Cumbres Formation dips gently to the west forming several faulted strips. It is organized in two facies: 1. fine-grained conglomerates composed of angular fragments of mylonites and deformed granites and 2. medium to fine-grained, polymictic conglomerates consisting of rounded fragments of pink and gray granitoids, deformed granitoids, schists, metavolcanics and milonites that predominate in the northern part. The facies define two dispersal systems: a southern system of angular pebbles and a northern, rounded pebble system. The outcrops of the two dispersal systems merge towards the east and southeast declining near the Uscamayo fault into the 'Bolsón de Pipanaco'. Several gravel composition maps with paleocurrent directions and maximum pebble sizes, show a dispersal system that, despite having its provenance in the surrounding ranges, is not adjusted with the present-day position of the ranges, suggesting that the system was emplaced in a north-south direction during the most intense phase of uplift in the early and middle Pleistocene.
\end{abstract}

Keywords: Pampean Ranges, Neogene gravel facies, Dispersion systems, Synsedimentary angular unconformities.

\section{Introducción}

La Formación Las Cumbres (Socic, 1972) aflora en las lomadas bajas y alargadas (denominadas 'cumbres' en la terminología local) ubicadas entre las sierras de Copacabana, Zapata, Vinquis y cerro Negro al norte, las sierras de Velasco-cerro La Punta al sur y la sierra de Paimán al oeste (Fig. 1). Los conglomerados de la Formación Las Cumbres yacen transicionalmente sobre la Formación Salicas (areniscas y limolitas castaño claras), portadora de mamíferos fósiles asignados a la edad mamífero Huayqueriense (entre los 9 y $6 \mathrm{Ma}$, Mule et al., 1997; Tauber, 2005). La Formación Salicas se apoya a su vez en no conformidad sobre la Peniplanicie Terciaria (González Bonorino, 1972). Esta unidad geomórfica, que rebautizamos en este trabajo como peniplanicie pampeana, fue labrada sobre el basamento cristalino. La Formación Las Cumbres forma una gran bajada dirigida hacia el este (Fig. 1) cuyos afloramientos culminan en un anillo de lomadas que se inicia junto al cerro Negro donde se denominan las Cumbres del Médano (límite de las Provincias de Catamarca y La Rioja), sigue hacia el este y luego hacia el sur, describiendo un arco que termina contra el faldeo oriental de la sierra de Velasco, sector donde son conocidas como Cumbres de los Pozuelos (Fig. 2). El presente trabajo analiza dos aspectos de esta unidad: 1. el sistema de dispersión, sus múltiples fuentes de aporte y particularmente la relación entre el área de dispersión (de afloramientos) y su relación con las serranías circundantes, que a su vez constituyen el área fuente; y 2. las facies y geometría de la sucesión aflorante en las Cumbres de los Pozuelos y su continuidad en las 'cumbres' que afloran con rumbo norte-sur, al oeste de la sierra de Velasco.

La geometría de la sucesión de conglomerados en las Cumbres de los Pozuelos se observa magníficamente en los extensos cortes de la ruta nacional 60 y el ex Ferrocarril General Belgrano (FCGB en la Fig. 1; separados por algunas decenas de metros), a unos $14 \mathrm{~km}$ al sur de la localidad de Alpasinche y en cortes naturales junto al río Colorado.

El basamento cristalino está integrado básicamente por metamorfitas de edad precámbrica tardía-cámbrica temprana, con milonitas devónicas y granitos ordovícicos y carboníferos. El basamento fue sometido durante un prolongado período, entre el Pérmico y el Neógeno temprano, a la erosión y pedimentación, a partir de lo cual se constituyó en el fondo de la cuenca neógena.

\section{Marco Tectónico}

La figura 3 muestra un esquema de las principales fallas asociadas a las terminaciones de las sierras de Velasco, cerro La Punta y Paimán, al sur y de Vinquis, Zapata y Copacabana, al norte. La falla principal de la región que divide el área en dos sectores es la falla Vinquis-Paimán (Fig. 3) que tiene un rumbo aproximadamente meridional con una fuerte inflexión hacia el oeste en la terminación austral de 


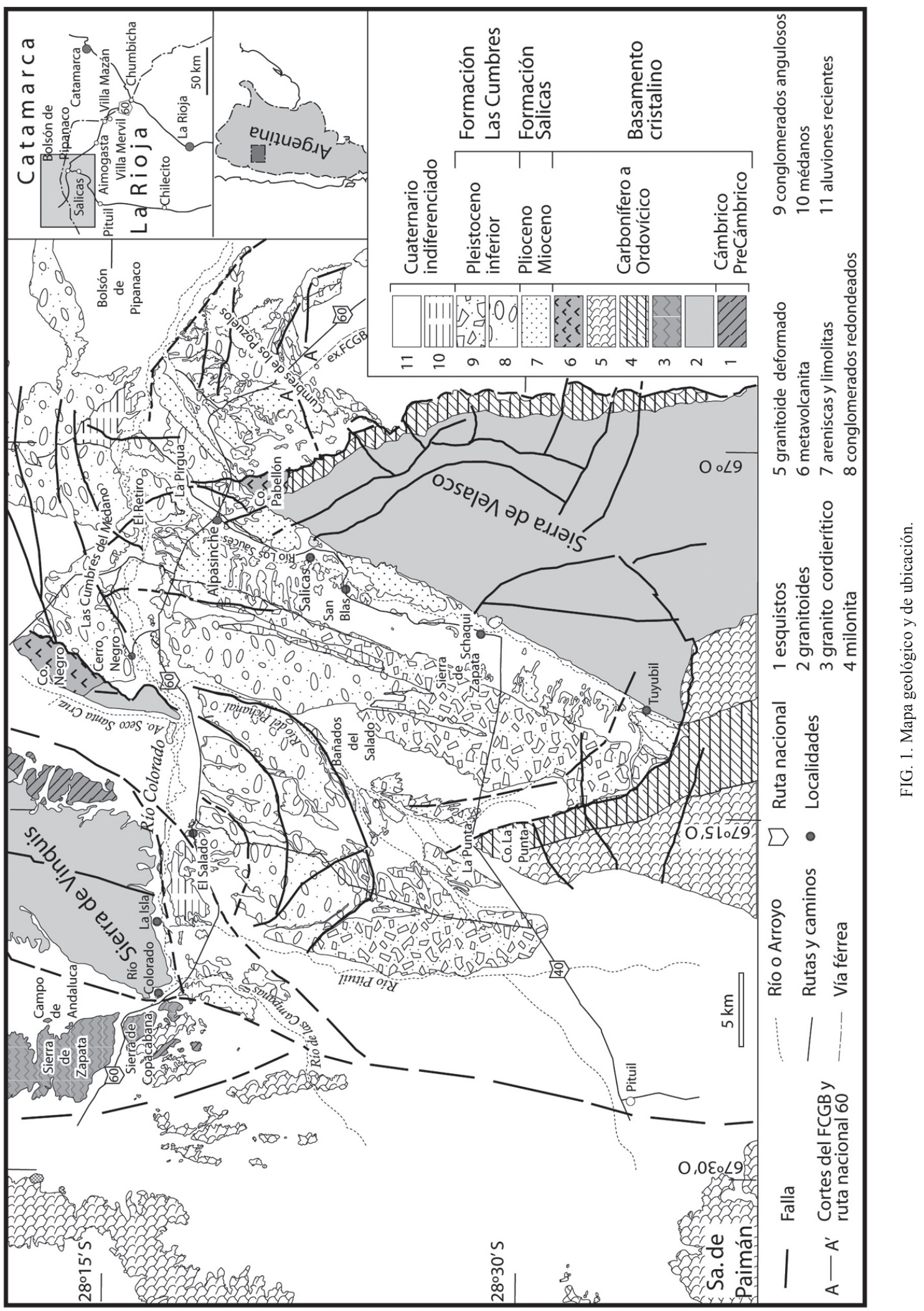




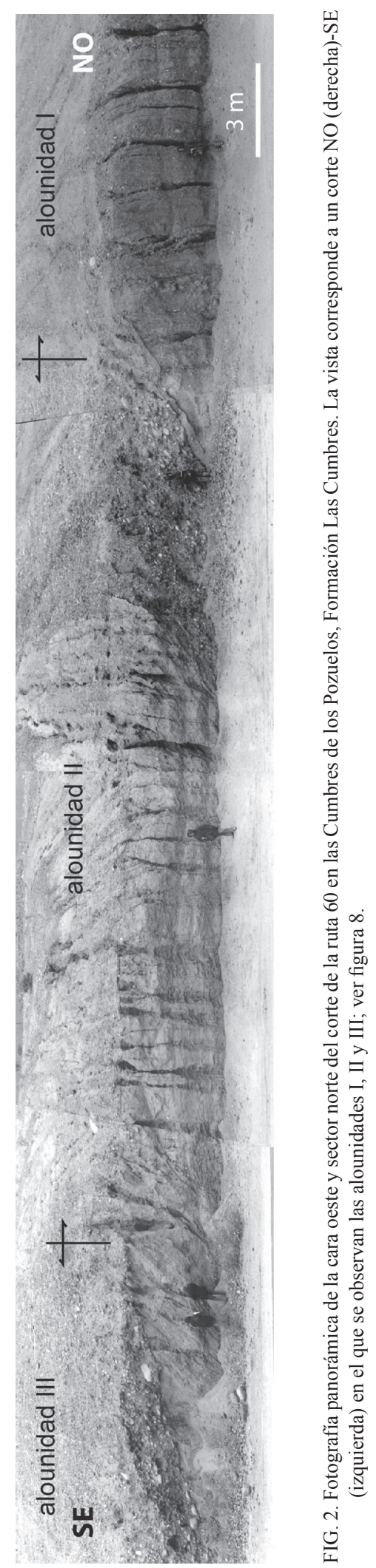

la sierra de Vinquis. La falla está acompañada de una serie de fallas con lineamientos curvos, una de las cuales afecta a las metavolcanitas y granitoides del cerro Negro y en menor escala a los afloramientos de la Formación Las Cumbres. La falla VinquisPaimán tiene un movimiento general levógiro con componente vertical de rechazo variable que se hace importante en los faldeos orientales de las sierras de Vinquis y Paimán. Las fallas secundarias curvas, al sur de la sierra de Vinquis, están relacionadas con el efecto transpresivo causado por el desplazamiento de la falla principal. El sistema de fallas Vinquis-Paimán corta un conjunto de fallas subparalelas (fallas La Punta, Velasco y Aimogasta) que tienen rumbo NNO-SSE; estas últimas son las causantes del desplazamiento hacia el norte de la Formación Salicas.

La falla Uscamayo está cortada en dos partes por la falla Aimogasta que ingresa por el cauce del río Colorado. Los bloques ubicados entre las fallas Velasco y Aimogasta que terminan en la falla diagonal Uscamayo tienen una historia particular con un fuerte desplazamiento hacia el sur y este, muy activo durante la depositación de la Formación Las Cumbres y que fue la causa de la formación de una serie de discordancias angulares de tipo progresivo en el labio hundido de esta falla (austral y oriental). El labio levantado de la falla Uscamayo contiene afloramientos de la Formación Salicas, que desarrolla pliegues suaves, con rumbo NNE-SSO (Fig. 3). El desplazamiento hacia el sur de este bloque está condicionado evidentemente por la actividad de la falla Aimogasta, que empujó hacia el SE a toda la sección oriental del área considerada. Este efecto y el desplazamiento dextrógiro de la falla Velasco, que movió el bloque de la sierra de Velasco hacia el norte, determinaron la intensa actividad desarrollada por la falla transpresional Uscamayo que produjo la acumulación de un gran espesor de conglomerados en su labio sur y este. La última etapa de deformación generó una serie de fallas paralelas con rumbo diagonal ONO-ESE que cortan la falla Uscamayo (Fig. 3).

\section{Estratigrafía}

\subsection{Introducción}

Han sido reconocidas en el área dos unidades estratigráficas: Salicas (inferior) y Las Cumbres (superior). La Formación Salicas, por su contenido fosilífero, es de edad pliocena mientras que los con- 


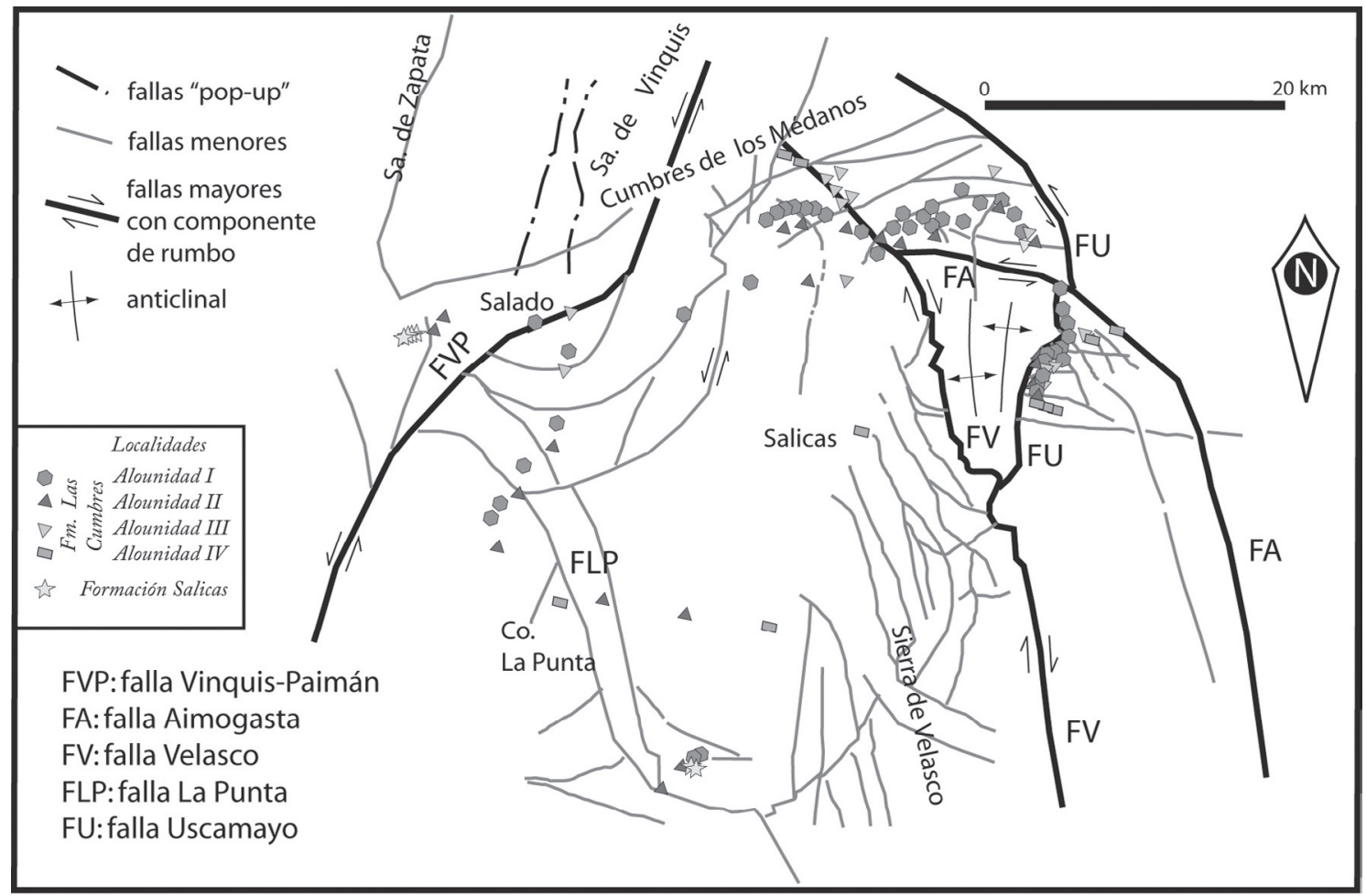

FIG. 3. Marco estructural de la región comprendida entre las sierras de Vinquis y Velasco. Además, se indican las ubicaciones de las localidades de muestreo: mediciones de tamaños de rodados y dirección de paleocorrientes.

glomerados de la Formación Las Cumbres no tienen una datación cierta, pero su techo es una superficie geomórfica razonablemente conservada, lo que permite ubicarla en el Pleistoceno. Ambas formaciones pueden ser correlacionadas con las formaciones Tamberías y Guanchín respectivamente, que afloran al oeste del área estudiada, en el Bolsón de Fiambalá y con edades comparables (Bossi et al., 1989; Sosa Gómez et al., 1993). Hacia el este en el valle de San Fernando de Catamarca, los afloramientos neógenos descritos por Nullo (1981), como formaciones Sanca y Concepción, son de muy escasa exposición. La Formación Concepción en particular, que aflora en el faldeo oriental de la sierra de Ambato, tiene características litológicas muy similares a las facies arenosas que presenta la Formación Las Cumbres en el área de Villa Mazán (28³9’S-66³2'45,61’O)Villa Mervil (2838'54”S-66³6’30”O).

\subsection{Formación Salicas}

La Formación Salicas está compuesta por areniscas finas, limolitas, algunas arcilitas y tobas, de color pardo rojizo claro o pardo amarillento claro, generalmente friables o poco consolidadas (Fig. 4). Se intercalan areniscas gruesas y conglomerados finos de escaso espesor, principalmente en su parte alta. El espesor medido de la formación en el área al SE de Alpasinche es de $440 \mathrm{~m}$ (sin base visible).

La unidad yace en no conformidad sobre la peniplanicie Pampeana labrada sobre el basamento granítico en la ladera occidental de la sierra de Velasco (entre Alpasinche y Schaqui y más al oeste en el Campo de Andaluca (Fig. 1)).

Han sido encontrados vertebrados fósiles (Notoungulados y Edentados) en varios niveles, de los cuales podemos destacar (Mulé et al., 1997): cf. Tremacyllus, Mesotheriidae indet., Pachyrukhinae indet. (dos especies).

Según Tauber (2005) la edad más probable es miocena tardía, pero como es bien conocido el carácter relíctico de esta fauna en las sucesiones neógenas de áreas clásicas como Villavil y Entre Ríos (Chiquimil), no puede ser descartada la edad pliocena para la unidad (Bossi et al., 1993, 2001). Las capas de tefras blancas de regular espesor 
Litología

\begin{tabular}{|c|c|}
\hline & conglomerado grueso \\
\hline & conglomerado fino \\
\hline & arenisca gruesa \\
\hline & arenisca mediana \\
\hline & arenisca fina \\
\hline & limolita \\
\hline$\hat{\wedge \wedge \wedge} \wedge$ & t toba \\
\hline & diatomita \\
\hline
\end{tabular}

\section{Estructuras primarias}

$=:=:=$ mal definida $]$ laminación

$\uparrow$ óndulas de corriente

— laminación odulada

$\mho \approx$ estr.cruzada en artesas

$\infty$ nidos de rodados

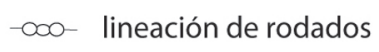

$\infty$ convoluciones

\& moldes de cristales de halita

\& rizoconcreciones

is calcretos

$\approx \quad$ vertebrados fósiles

$\triangle \quad$ restos vegetales

$\lambda$ marcas de raíces

dirección de paleocorrientes

\section{Contactos}

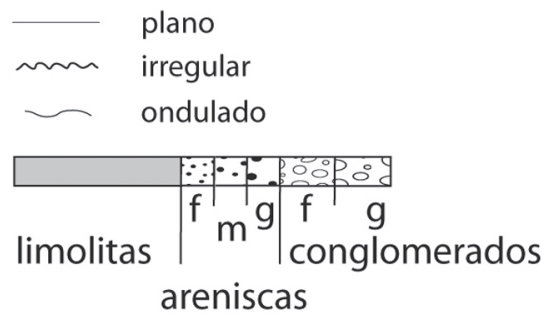

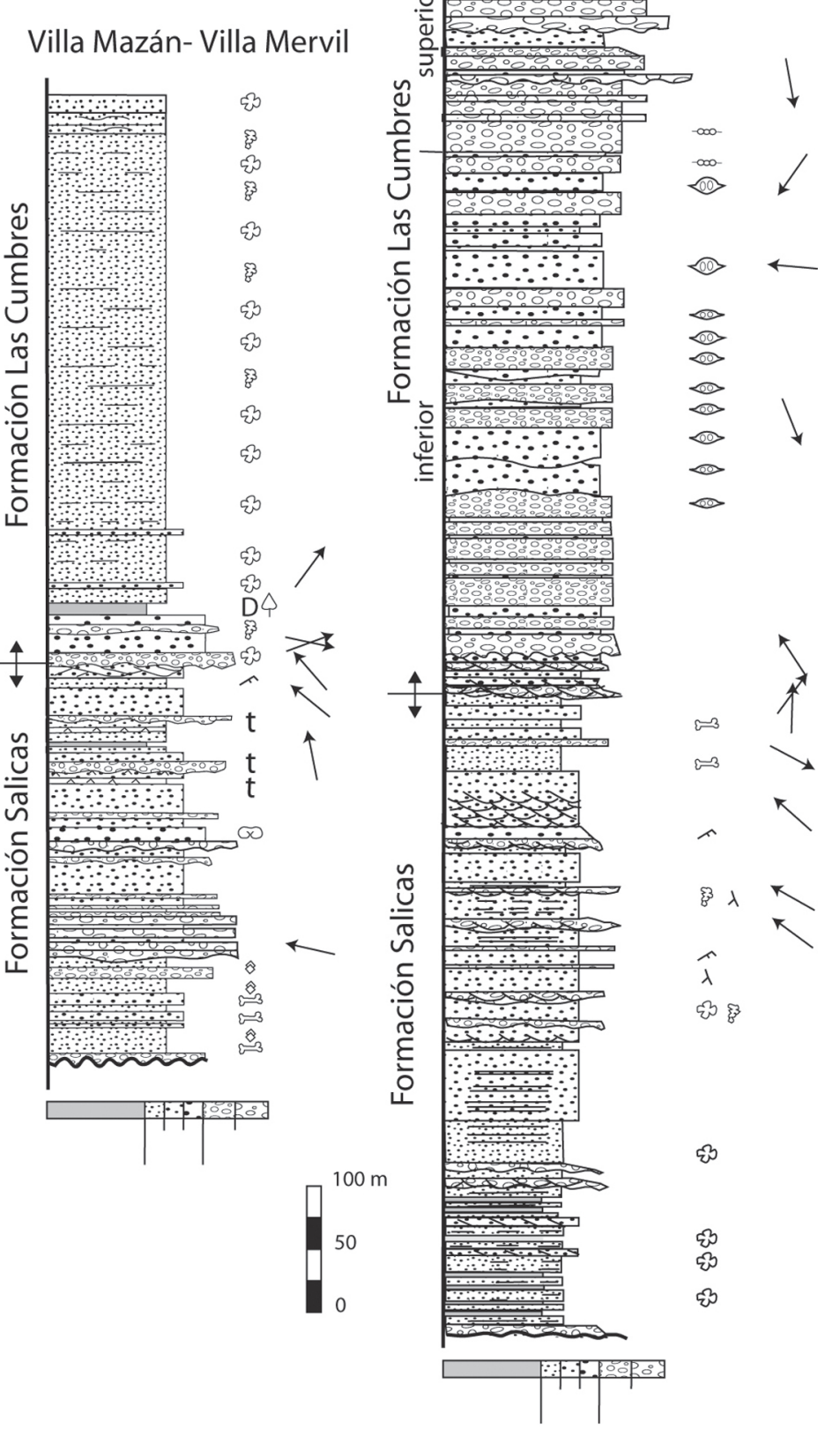

FIG. 4. Perfil estratigráfico relevado en la sucesión neógena, entre la base de la Formación Salicas en el extremo norte de la sierra de Velasco y el tope de la Formación Las Cumbres en las Cumbres del Médano por la ruta nacional 40. 
que son un rasgo típico de esta unidad, aparecen únicamente en las sucesiones de edad miocena superior-pliocena (entre 7 y 2,9 Ma) de los valles Calchaquíes, ubicados más al norte (Bossi et al., 2001). En relación con los depósitos neógenos de la vecina Cuenca de Santa María-Hualfín (Bossi et al., 1993, 2001), estos restos corresponderían a la fauna encontrada en la Formación Chiquimil (areniscas amarillas, ver Muruaga, 1998) y que corresponden a la parte basal del Araucanense de González Bonorino (1972).

\subsection{Formación Las Cumbres}

La unidad es muy heterogénea en su desarrollo estratigráfico. Aflora en una amplia región de 'cumbres' dispuestas entre la sierra de Vinquis, cerro Negro, sierra de Velasco y cerro La Punta. Las capas al oeste de la sierra de Velasco, mantean (buzan) suavemente hacia el oeste y están dispuestas en bloques separados por fallas norte-sur que al sur de la sierra de Vinquis adoptan un diseño curvado. En las Cumbres del Médano la sucesión es granocreciente, estratocreciente y desarrolla un homoclinal que mantea al norte. El techo es la superficie geomórfica original y la base es un contacto transicional con la subyacente Formación Salicas, que se manifiesta un poco al norte de la traza de la ruta nacional 60 . El espesor máximo medido es de $600 \mathrm{~m}$ (Fig. 4), en el perfil sobre la ruta nacional 40 , en el tramo que cruza las Cumbres del Médano.

En las lomadas ubicadas al oeste de Salicas y San Blas, los conglomerados son finos con guijas y guijarros angulosos de milonitas, granitos deformados $\mathrm{y}$ en menor proporción granitoides rosados y grises. $\mathrm{Al}$ oeste de San Blas, aparece una intercalación lacustre de limolitas y arcillitas verde amarillentas claras. Las capas tienen rumbo norte-sur manteando suavemente hacia el oeste. Este episodio lacustre, que parece ser muy local, puede paralelizarse con otros similares, ya mencionados, ubicados más al sur fuera del área de estudio, en la sierra de Mazán (284ㅇ'S-66³6'O).

La relación con la subyacente Formación Salicas, de edad pliocena, y la presencia de una superficie geomórfica en su techo ha inducido a otros investigadores (Sosic, 1972; González Bonorino, 1972) a aceptar una edad pleistocena temprana. Las placas de dacipódidos de edad pleistocena encontrados en las capas lacustres de San Blasito, confirman esta edad.
En el perfil Las Cumbres-Alpasinche de la figura 4 se pueden considerar dos secciones:

Inferior: constituida por areniscas medianas a gruesas que forman niveles tabulares de base irregular de 2 a $3 \mathrm{~m}$ de espesor, a veces terminados en barrancas abruptas contra depósitos arenosos finos y escasas limolitas (espesor $430 \mathrm{~m}$ ).

Superior: compuesta casi exclusivamente por conglomerados en disposición granocreciente. Los conglomerados son polimícticos, de guijas y guijarros, subredondeados y redondeados con ocasionales guijones y bloques concentrados en la base de los estratos. La imbricación es manifiesta y los conglomerados en su gran mayoría son clastosoportantes. La composición de los rodados es variable. Los rodados predominantes son de granitoides grises y rosados (60 y $80 \%$ ), esquistos y metavolcanitas (10-25\%) y volcanitas dacíticas y andesíticas (10-14\%). El espesor de esta sección es de $170 \mathrm{~m}$.

Entre el cerro La Punta y el faldeo occidental de la sierra de Velasco, a la altura del paraje conocido como Tuyubil (Fig. 1), aparecen conglomerados matriz soportados, compuestos por guijas subangulosas (45\%), guijarros (20\%) y guijones $(5 \%)$. La estratificación es tabular irregular en capas de 0,2 a $0,5 \mathrm{~m}$ de espesor. Alternan con areniscas sabulíticas (con alteraciones tipo corteza de pan). Algunos sectores muestran estratificación cruzada planar asociada a laminación de bajo ángulo y paralela. Hacia el norte, a lo largo de la ruta 40, los conglomerados matriz soportantes contienen guijas y guijarros angulosos, y matriz de arena gruesa sabulítica. Las capas son lenticulares irregulares con estratificación cruzada en artesas; alternan con conglomerados clastosoportantes de guijarros angulosos y matriz arenosa media y/o areniscas finas a medias mal seleccionadas, macizas con abundante sábulo y guijas dispersas.

En el borde oeste del área aflorante, en las lomadas ubicadas entre el camino de Pituil a El Salado y el cauce del río Pituil (Fig. 1), afloran facies arenosas medias a sabulíticas, cuarzo-feldespáticas con guijas y guijarros angulosos dispersos (20\%) y cementación carbonática irregular en capas de 0,2 a $0,3 \mathrm{~m}$. Alternan con lentes de conglomerados clastosoportados de guijas angulosas y guijarros subangulosos a subredondeados y bloques de granitoides redondeados en capas tabulares irregulares de 0,2 a 0,4 m. En estas lomadas cercanas al cauce del río Pituil aparecen asociados grandes bloques 
sobredimensionados ( 0,8 a 1,5 m de largo máximo) de milonitas angulosas.

En el sector NO del área de afloramientos, entre el río Las Campanas y El Salado (Fig. 1), alternan conglomerados de guijarros clastosoportados y matriz soportados. La matriz es arenosa gruesasabulítica, la composición dominante es granítica. Algunos clastos son guijones y bloques redondeados, dispersos o formando lentes irregulares. Además, se observan capas clastosoportadas de guijas subredondeadas a subangulosas con espesores de 0,2 a $0,4 \mathrm{~m}$ con guijarros y guijones redondeados dispersos. La cementación carbonática suele estar presente formando costras irregulares.

En las cercanías de la localidad de El Salado y la ruta 60 , existe una alternancia de estratos de conglomerados y areniscas. Los primeros pueden ser de dos tipos: a. estratos tabulares irregulares de conglomerados guijarrosos subangulosos y subredondeados matriz soportados $\mathrm{y}, \mathbf{b}$. conglomerados clastosoportados de guijones y bloques subredondeados a redondeados, en capas de 0,3 a $1 \mathrm{~m}$ de espesor. Por otra parte, los estratos psamíticos están formados por areniscas gruesas con abundantes gránulos y guijas dispersas, en capas lenticulares de 0,2 a $0,3 \mathrm{~m}$ con laminación paralela o en artesa. Algunos cuerpos conglomerádicos espesos (1 a $3 \mathrm{~m}$ de espesor) con gradación normal, muestran concentraciones de guijarros y bloques apoyados sobre una base plana. La cementación carbonática está presente en forma de núcleos irregulares. Los cuerpos espesos con gradación normal suelen destacarse por su tabularidad, continuidad y regularidad.

Al sur del cerro Negro por la ruta nacional 60 , la Formación Las Cumbres se inicia con areniscas medias a gruesas con abundantes gránulos y escasas guijas con estratificación cruzada en artesas grandes y de bajo ángulo en capas lenticulares de $0,2 \mathrm{a}$ $0,5 \mathrm{~m}$ que alternan con conglomerados de guijarros $\mathrm{y}$ guijones subredondeados clastosoportantes en capas de 0,3 a 0,5 m y escasos bloques. La matriz es arenosa gruesa sabulítica y no supera el $30 \%$.

En los afloramientos de la vieja traza de la ruta 40, cercana al cerro Negro en los niveles con los cuales culmina la sucesión del perfil presentado en la figura 4, aparecen los conglomerados más gruesos, compuestos por un entramado de guijarros y guijones clastosoportantes, subredondeados y redondeados y abundantes bloques (de 0,3 a $1 \mathrm{~m}$ de largo máximo) en capas tabulares y lenticulares irregulares de 0,5 a $1 \mathrm{~m}$. La imbricación es pobre debido a la gran abundancia de rodados ecuantes de granitoides rosados y grises.

El sector este del área aflorante a lo largo de las Cumbres de los Pozuelos, tiene un desarrollo anómalo que se refleja en su particular geometría interna y también en el tamaño máximo de los rodados, que aumenta considerablemente, alterando el habitual decrecimiento de tamaños que opera en las formaciones sedimentarias psefíticas de pie de monte.

En el anillo de lomadas ubicado al este del cauce del río Colorado (Fig. 5) que termina en las Cumbres de los Pozuelos, la sucesión está fraccionada en un conjunto de alounidades asociadas mediante discordancias angulares de neto corte sinsedimentario. Aparecen expuestas muy claramente en los cortes de la ruta 60 (Fig. 2) y del ex FCGB, allí donde cruzan las lomadas de las Cumbres de los Pozuelos y en las vecindades del cauce del río Colorado un poco más al este (Fig. 5).

Considerando los conglomerados a una escala regional, pueden distinguirse dos facies de conglomerados, que afloran entre las sierras de Vinquis y Velasco (Fig. 6): redondeados y angulosos. Los conglomerados redondeados provienen del sector NO mientras que los angulosos derivan de la sierra de Paimán, cerro La Punta y sierra de Velasco. En la imagen satelital se ha observado el contraste de tonos entre estas facies (los conglomerados angulosos son más oscuros) y la interdigitación que opera entre ambas al sur de la ruta nacional 60 .

Existen suficientes elementos para indicar que el ambiente depositacional era dominado por un clima árido, con áreas fuentes cercanas constituidas por montañas en activo ascenso. La presencia de carbonato sinsedimentario (calcretos y rizoconcreciones) se interpreta como producto de procesos freáticoedáficos en un clima árido. La gran extensión de conglomerados indica un transporte masivo de gran penetración en la cuenca vecina definida por el Bolsón de Pipanaco. El enorme volumen de conglomerados acumulados en una región tan extensa, implica una producción de cascajo en el área fuente muy superior a la actual. En parte puede atribuirse a un ambiente tectónico muy activo, pero también podría adicionarse un clima árido con un invierno muy riguroso y frío. Esta característica es típica de los conglomerados de las sierras Pampeanas noroccidentales y está relacionada con el clímax del ascenso de los bloques de montaña designados colectivamente como 'Punaschotter' por Penck (1920). 


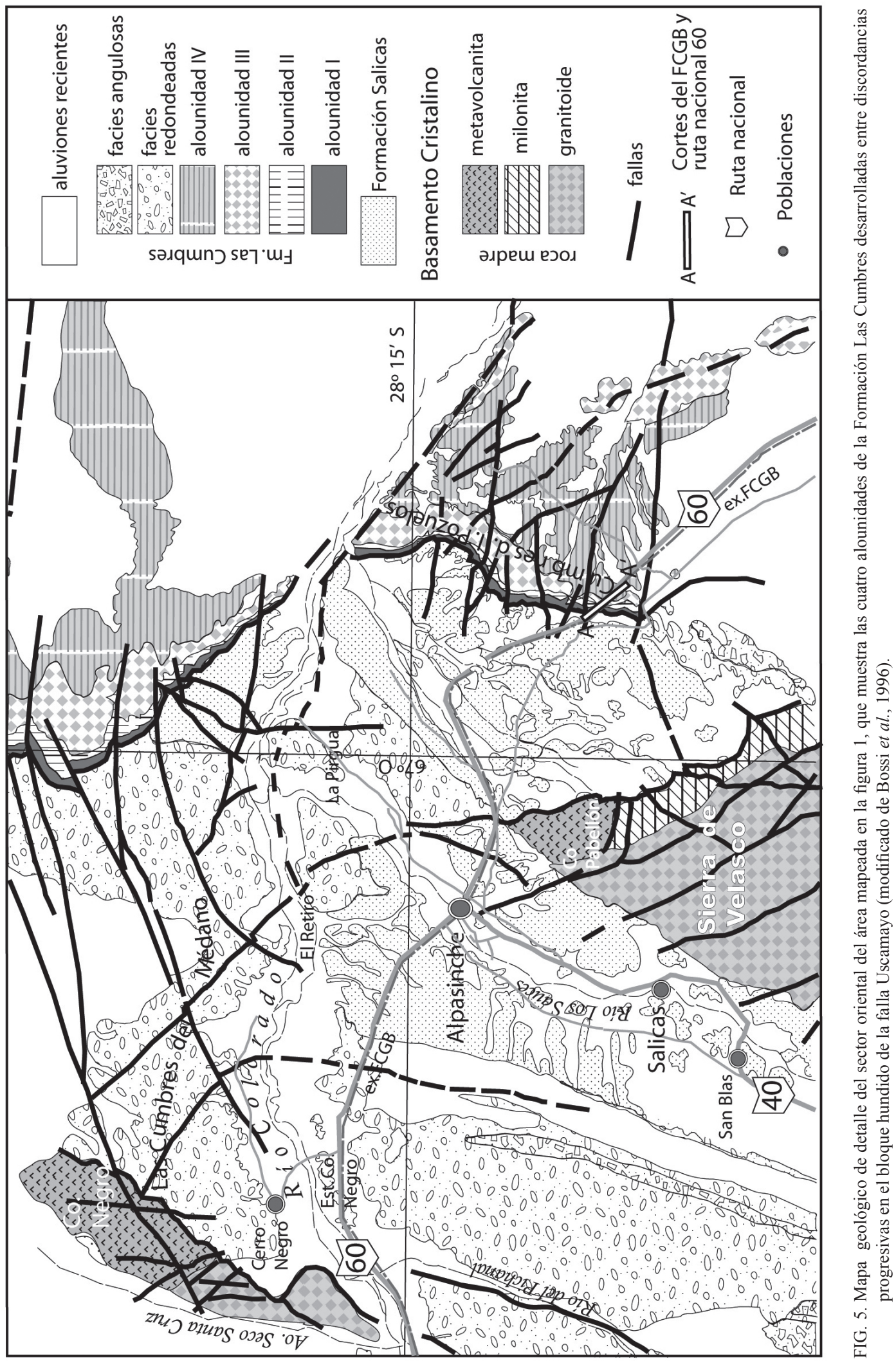



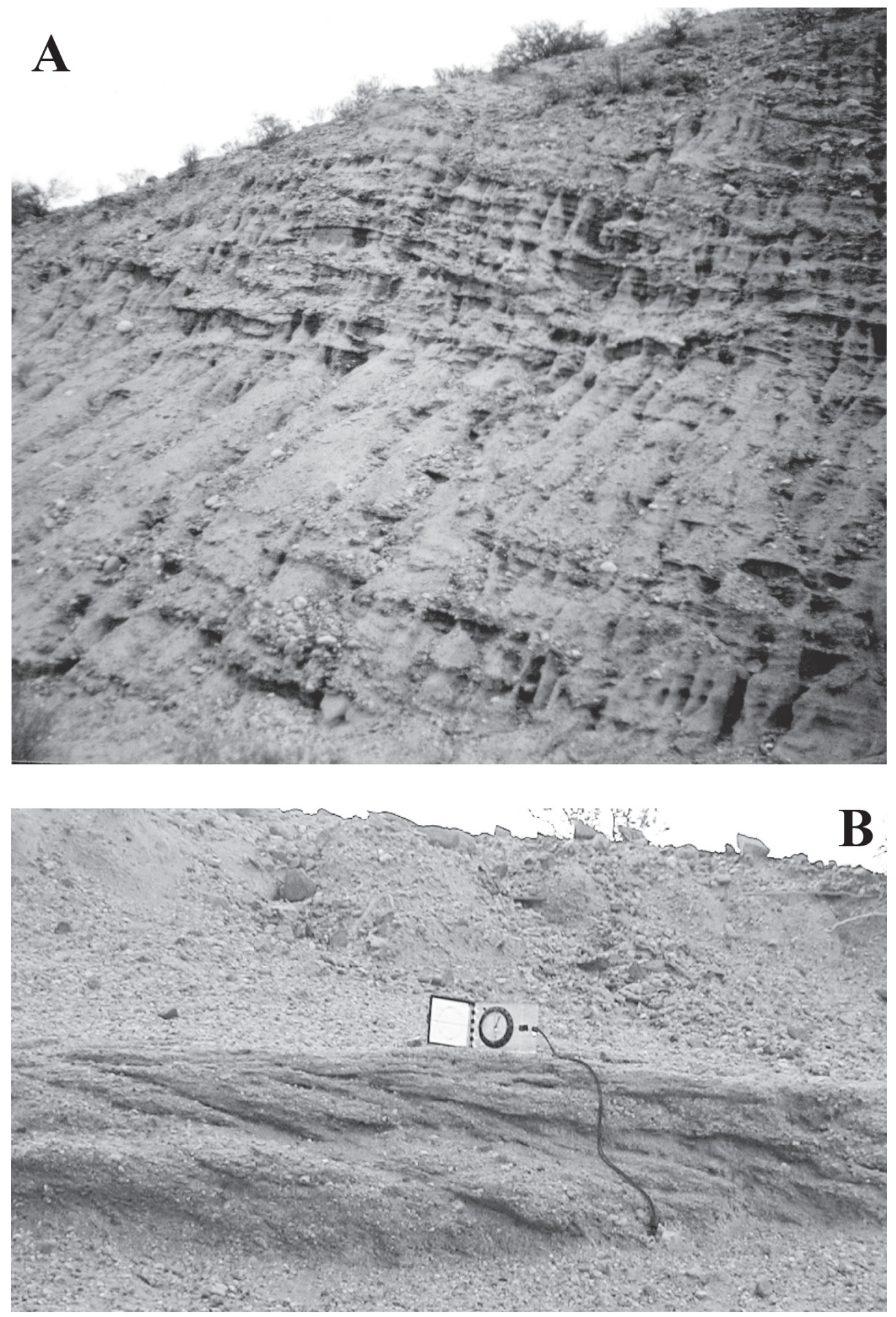

FIG. 6. A. Conglomerados redondeados en el tope de la sucesión de la Formación Las Cumbres (perfil de la figura 4) en el corte de la ruta nacional 40 sobre las Cumbres del Médano; B. Conglomerado matriz soportado de guijas angulosas, formando capas lenticulares irregulares de 0,2 a 0,3 m con estratificación cruzada o suavemente inclinada. Parte de una barra de escaso relieve en un canal enlazado gravoso posiblemente efímero. 


\section{Alounidades Junto a la Falla Uscamayo}

El sector oriental de la faja aflorante presenta una particular organización generada por la actividad tectónica de la falla Uscamayo en su bloque hundido ubicado al sur y este. Este aspecto se discute con detalle considerando la importancia de la estructura desarrollada, que se puede considerar única en esta parte de las Sierras Pampeanas Nordoccidentales.

Se han reconocido cuatro facies en la Formación Las Cumbres:

- CG: capas de conglomerados medios a gruesos clastosoportantes (Fig. 7A), formadas por guijas y guijarros de composición granítica $(60 \%)$, metamórfica $(25 \%)$ y volcánica $(15 \%)$, con rodados redondeados ecuantes y en menor proporción discoidales imbricados y algunos sobredimensionados (30 a $80 \mathrm{~cm})$. La imbricación es por lo general pobre, pero en algunos lugares se aprecian disposiciones en dobletes o tripletes de rodados discoidales y entramados de tipo a(t)b(i) (el eje a del rodado es transversal a la corriente y el eje b del rodado está imbricado). Las capas son métricas, de contactos basales irregulares, con cortes y rellenos en sus bases y textura granocreciente. Las facies CG forman cuerpos multiepisódicos de espesor variable entre 1 y $10 \mathrm{~m}$. El entramado es bien seleccionado, con una concentración elevada de guijones y escasa matriz areno-granulosa. Estas facies contrastan netamente con las restantes, donde los guijones aparecen aislados y volumétricamente son minoritarios.

- CS1: areniscas gruesas guijosas-granulosas intercaladas con conglomerados de guijas (y pocos guijarros redondeados) en capas de 0,4 a $1 \mathrm{~m}$ de espesor (Fig. 7B). Están compuestas de dobletes gra$\mathrm{va} /$ arena en capas tabulares irregulares de $0,50 \mathrm{~m}$ de espesor. La parte gravosa de la dupla está constituida por guijas redondeadas y guijarros subredondeados y algunos guijones aislados con un entramado imbricado muy pobre de tipo $a(t) b(i)$. La parte arenosa es gruesa, rica en gránulos y guijas pequeñas con arreglo granodecreciente y laminación paralela mal definida.

- CS2: duplas de capas de sabulitas a conglomerados de guijas, con abundante matriz arenosa gruesa, clastos muy angulosos y laminación paralela mal definida, en capas tabulares irregulares métricas a decimétricas, alternantes con otras similares con textura más gruesa (guijas y guijarros angulosos) en capas tabulares de escala decimétrica (Fig. 7C). Es- tas facies aparecen exclusivamente en la alounidad IV (Fig. 5). Composicionalmente y por su geometría organizada en duplas de textura cambiante, son parecidas a las facies CS1, pero difieren en la manifiesta angularidad de sus clastos. La composición es predominatemente granítica. Fuera del corte, en las Cumbres de los Pozuelos, el mismo tipo de facies aflora al oeste del la sierra de Velasco entre San Blasito y el río Pituil.

- S: areniscas finas a medias (Fig. 7D) con laminación paralela mal definida, en capas de 0,2 a $0,4 \mathrm{~m}$, con pocas estratificaciones cruzadas planares. Las sedimentitas son generalmente friables, pero tienen intercalados algunos niveles muy delgados con cementación carbonática. Estas facies aparecen en la alounidad II y en forma muy subordinada en la alounidad III (Figs. 5 y 8). Sobreyacen siempre a las facies CG.

\section{Análisis de las Alounidades}

En la sucesión de conglomerados y areniscas gruesas sabulíticas se pueden distinguir cuatro secuencias depositacionales separadas por tres discordancias sinsedimentarias y angulares (Riba Arderiu, 1989), que por ser las de mayor jerarquía han sido denominadas aquí de primer orden $(\mathrm{a}, \mathrm{d}, \mathrm{h})$, con buzamientos de $45^{\circ}, 24^{\circ}$ y $15^{\circ}$, respectivamente (ver las Figs. 2 y 8). Las cuatro alounidades son de extensión local y se definen estrictamente para el área de las Cumbres de los Pozuelos. A su vez, dentro de cada alounidad aparecen discordancias menores que denominamos de segundo orden (b, c, e, f, g). Estas discordancias de segundo orden dividen las alounidades en unidades menores y están afectadas a su vez por fallas sinsedimentarias (Fig. 8). Debido a la presencia de erosión y pedimentación relacionados con hiatus de extensión variable (representados por las discordancias) y de repeticiones por falla, es difícil medir el espesor real de estas alounidades. El espesor total cercano a $400 \mathrm{~m}$ ha sido estimado a partir del perfil de la figura 4.

La definición formal en aloformación y alomiembros (sensu 'North American Comission of Stratigraphic Nomenclature', 1983, o secuencias y subsecuencias del Comité Argentino de Estratigrafía, 1992) no ha sido encarada por el momento, debido a que la presencia de tantas alounidades de diferente jerarquía haría engorrosa la asignación de nombres toponímicos a cada uno de estos elemen- 
tos. Al respecto denominamos simplemente a las unidades separadas por discordancias de $1^{\circ}$ orden: alounidades de $1^{\circ}$ orden y a las unidades separadas por discordancias de $2^{\circ}$ orden: alounidades de $2^{\circ}$ orden. Las alounidades cualesquiera sea su orden han sido numeradas de base a techo (Fig. 5).

\subsection{Alounidad de $1^{\circ}$ Orden: I}

Está repetida por una falla (Fig. 8) y está compuesta principalmente por facies CS1 (Fig. 7B) en capas subverticales a ligeramente invertidas. La base no es visible y el techo es una neta discordancia con la alounidad de $1^{\circ}$ orden: II. Las duplas de conglomerado-arenisca suelen presentar imbricación en los clastos mayores, que indica una dirección de paleocorrientes hacia el sur (dirigidas hacia abajo en el afloramiento). El espesor estimado es de $80 \mathrm{~m}$.

\subsection{Alounidad de $1^{\circ}$ Orden: II}

Está compuesta por una alternancia de facies CG (Fig. 7A) con potentes niveles de facies S, con $32 \mathrm{~m}$ de espesor visible (Fig. 7D). Esta alounidad
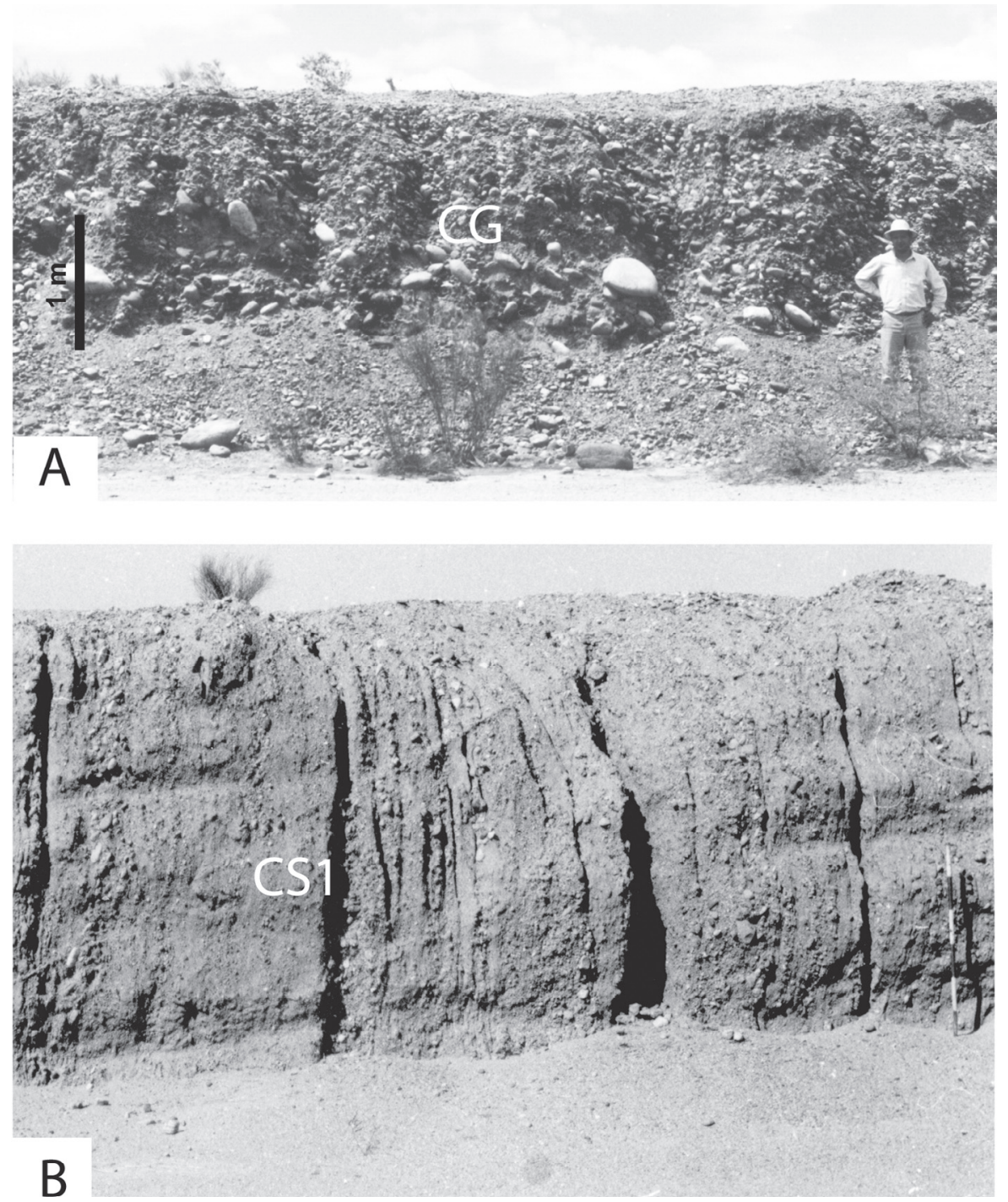

FIG. 7. A. Conglomerado (facies CG) clastosoportante de guijarros y bloques con abundantes bloques redondeados en el corte de la ruta 60 en las Cumbres de los Pozuelos; B. Dobletes arena gruesa y grava fina (facies CS1), en posición vertical dentro de la alounidad I. 
de $1^{\circ}$ orden se inicia con un estrato de $3 \mathrm{~m}$ compuesto por facies CG y está conformada por tres alounidades de $2^{\circ}$ orden. La disposición de las alounidades de $2^{\circ}$ orden es alterada parcialmente por la presencia de fallas (Fig. 8). En la base de la alounidad II (de $1^{\circ}$ orden) se ubican los conglomerados de bloques con los rodados de mayor tamaño observado (sobredimensionados).
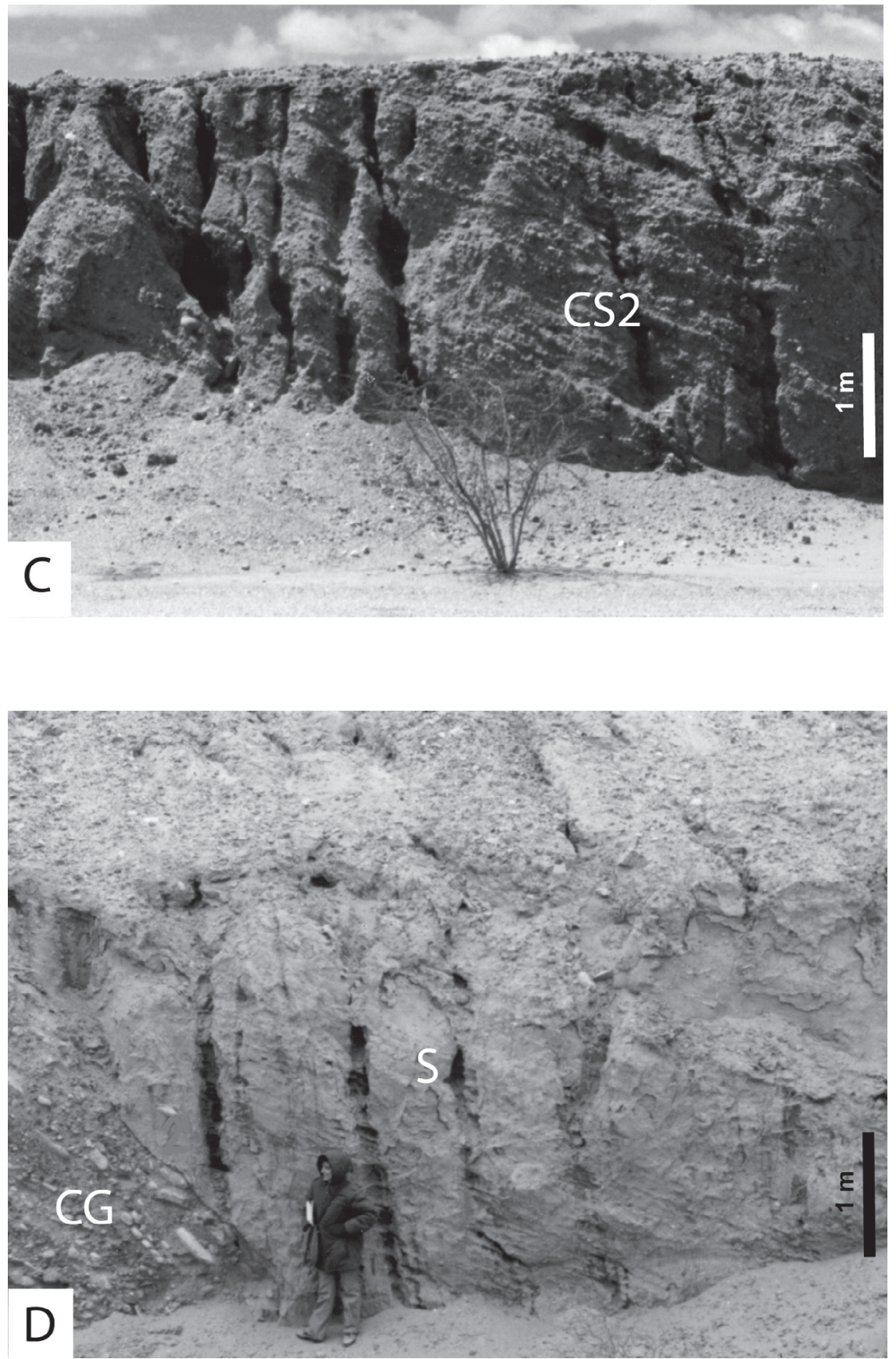

FIG. 7. C. Conglomerados finos angulosos (facies CS2) pertenecientes a la alounidad IV y D. Las facies arenosas (S) yaciendo sobre los conglomerados de la facies CG, pertenecientes a la alounidad II. 

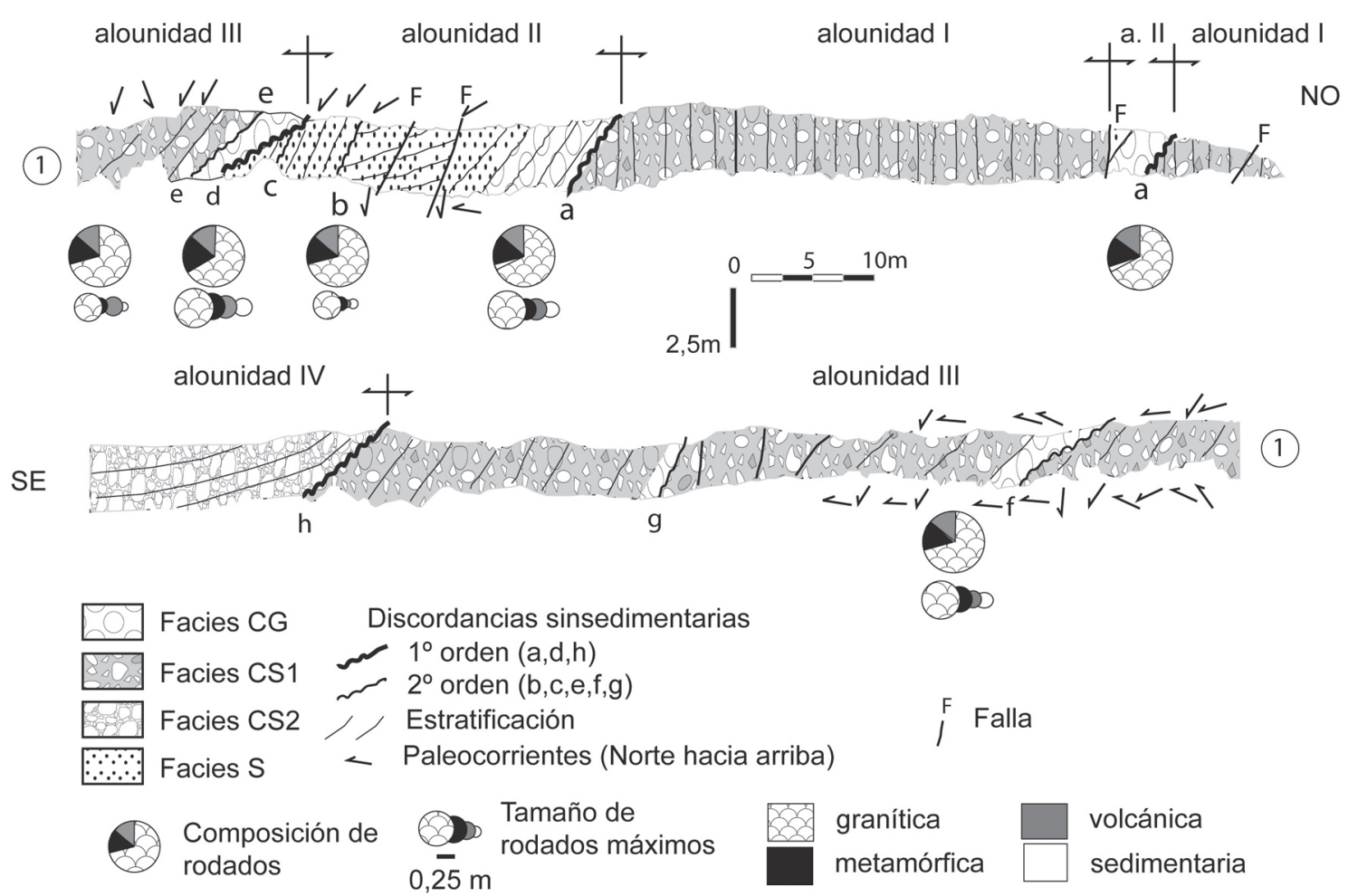

volcánica

sedimentaria

FIG. 8. Perfil estructural del corte de la ruta 60, sobre las Cumbres de los Pozuelos.

\subsection{Alounidad de $1^{\circ}$ Orden: III}

Está compuesta casi exclusivamente por facies CS1 que presentan un espesor visible de $30 \mathrm{~m}$. Dentro de la alounidad III (de $1^{\circ}$ orden) pueden distinguirse cuatro alounidades de $2^{\circ}$ orden, y cada una se inicia con espesos estratos de facies CG. La alounidad inferior (de $2^{\circ}$ orden) tiene un manteo de $25^{\circ}$ y la alounidad superior (de $2^{\circ}$ orden) alcanza valores de $70^{\circ}$ (Figs. 2 y 8 ). En el corte del ferrocarril es posible observar la presencia de las facies $\mathrm{S}$, en la alounidad superior (de $2^{\circ}$ orden).

\subsection{Alounidad de $1^{\circ}$ Orden: IV}

Está compuesta exclusivamente por facies CS2 (Fig. 7C) y presenta un espesor visible de $8 \mathrm{~m}$. El tope de esta alounidad es una superficie geomórfica que mantea suavemente $\left(5^{\circ}\right)$ hacia el sur al igual que los estratos subyacentes.

\section{Interpretacion de las facies}

Las facies CG se interpretan como gravas de rezago ('lag gravels') que corresponden a procesos secundarios de pedimentación del bloque colgante de la falla Uscamayo, donde se acumularon buena parte de las facies medias y distales de una gran bajada a la que pertenecían estos conglomerados (Fig. 7A). Los materiales concentrados son los más gruesos y posiblemente superan por su tamaño la predecible competencia de los flujos involucrados en las facies CS1, CS2 y S (Fig. 7B a Fig. 7D) que constituyen el volumen mayor acumulado. Aunque en menor proporción es posible encontrar bloques de limolitas rojizas arrancados de la Formación Salicas expuesta parcialmente en el proceso de pedimentación.

Las duplas de facies CS1 caracterizan en forma exclusiva a la alounidad I y parte de la alounidad III. Aunque las bases son irregulares y erosivas, tienen escaso relieve y no presentan evidencias de canalización o de cortes y rellenos de canales menores. La repetición de facies (duplas CS1) puede asignarse a la participación de mantos decrecientes asociados a flujos mixtos hiperconcentrados (Gani, 2004) que se derramaban sobre la superficie de la bajada constituida por varios abanicos coalescentes ('sheet floods', in Blair y McPherson, 1994 y Wells y Harvey, 1987). 
Las facies CS2 son similares a las CS1, en textura y organización estructural, pero difieren en la marcada angularidad de sus clastos. Están compuestas casi exclusivamente por granitos milonitizados que afloran en la parte media de la sierra de Velasco, entre ésta y el cerro La Punta.

Las facies $\mathrm{S}$, por último, corresponden a mantos de arena depositados por flujos ácueos no canalizados, con elevada carga de sedimentos, cuando menguaba la creciente. Estas facies que caracterizan la parte media de la alounidad II, fueron acumuladas inmediatamente encima de las facies CG, que representan depósitos de rezago, formados en las etapas de pedimentación. El hecho de que estas facies no contengan una cantidad significativa de rodados, indica que hubo un cambio en las condiciones de sedimentación, con fuerte retracción areal de los conglomerados. El área de las actuales Cumbres de los Pozuelos, quedó fuera del borde de los abanicos y posiblemente integraba la vecina planicie de distributarios que sigue a éstos, pendiente abajo.

\section{Tectónica y sedimentación}

Es evidente que existe un hiatus muy prolongado entre las alounidades I y II (como se desprende de la arquitectura de la pared oeste en el corte de la ruta 60 (Figs. 2 y 7). La sucesión de la alounidad I no contiene facies de rezago (CG) y es evidentemente más espesa que las otras, además de presentar una deformación más intensa. Esta situación asocia a la alounidad I con el clímax de la actividad tectónica que fue la generadora de una fuerte compresión y la elevación de bloques de montaña al NO y la formación de una extensa bajada que se extendía hacia el este y sureste. Estos niveles de penetración de los conglomerados en las cuencas intermontanas (actuales 'bolsones') sólo tuvieron vigencia durante la acumulación de los Conglomerados de la Puna (Punaschotter, de Penck, 1916 in Bodenbender, 1924), asociados a un clima de aridez creciente y a una gran disponibilidad de cascajo de ladera. Los rodados sobredimensionados aparecen aislados en los dobletes grava/arena de las facies CS1 (Fig. 7B) y son el evidente repositorio de las facies CG (Fig. 7A), acumuladas como rezago de una intensa peniplanización.

En las Cumbres de los Pozuelos las facies CS1 y CS2 (Fig. 7B y Fig. 7C) constituyen los depósitos distales de una gran bajada, cuyas cabeceras se en- contraban entre 20 y $50 \mathrm{~km}$ al oeste (Fig. 9). Estas facies están asociadas a mantos de creciente y tienen escasa evidencia de retrabajado superficial. En los períodos de mayor actividad de la falla Uscamayo, la superficie de la bajada cercana a ésta era sometida a pedimentación, con intensa remoción de los sedimentos preexistentes, y acumulación de las gravas de rezago definidas por las facies CG (Fig. 7A).

La alounidad II tiene además varias fallas sinsedimentarias que afectan los depósitos arenosos (facies S, Fig. 7C). Según Blair (1987) la arena es transportada selectivamente como carga de lecho en una serie de pulsos dentro de ondas estacionarias supercríticas en condiciones de máxima profundidad y velocidad de la corriente. Existe manifiesta oblicuidad entre las paleocorrientes medidas en las facies $S$ respecto a las presentadas por las facies $C G$ y CS1, ubicadas respectivamente abajo y arriba (ver relaciones de las alounidades I y II en la figura 8). Esta relación puede tener otras implicancias como el desarrollo de antidunas o acreción a sotavento, con un ángulo grande respecto a la dirección principal de flujo y asociada a los abultamientos formados por ondas estacionarias (Middleton, 1965; Zielinski, 1982).

De lo expuesto podemos colegir que cada secuencia (con la excepción de la alounidad IV) se inicia con las facies CG apoyadas sobre una superficie discordante irregular, que son rápidamente reemplazadas por las facies $\mathrm{S}$ o CS1, según sea el caso (Fig. 8). La alounidad II muestra el mayor contraste facial, pues pasa de las facies CG con abundantes rodados sobredimensionados, a las facies $\mathrm{S}$ de naturaleza arenosa.

Las facies primarias (Blair y McPherson, 1999), identificadas como CS1, CS2 y S en los cortes de las Cumbres de los Pozuelos, son de tipo distal en un clásico abanico aluvial acumulado en un clima árido. Por su parte las facies de conglomerados que aparecen en los cortes de la ruta nacional 40 (nueva y vieja traza) sobre las Cumbres del Médano, son mucho más gruesas y pueden considerarse de naturaleza proximal. La posición estratigráfica es similar, pues en ambos casos los conglomerados involucrados corresponden estratigráficamente a la parte alta de la sucesión, justo debajo de la superficie geomórfica inclinada hacia el norte, que define el tope de la unidad (Fig. 1).

Los rodados de estos conglomerados cuspidales de la Formación Las Cumbres, son de petrografía 
variada. En particular, las metavolcanitas de la punta de la sierra de Velasco y del vecino cerro Negro están ausentes. Las volcanitas provienen de centros volcánicos de edad miocena ubicados entre las sierras de Vinquis y Zapata.

La figura 5 muestra el marco geológico de la región oriental de los afloramientos de la Formación Las Cumbres, con las tres fallas más importantes que controlaron la sedimentación en el área de las Cumbres de los Pozuelos, denominadas por Bossi et al. (1996): Velasco, Aimogasta y Uscamayo (Fig. 3). El desplazamiento relativo de estas fallas se manifiesta particularmente a lo largo de la falla Uscamayo, cuyo carácter transpresivo produjo un bloque hundido dividido en dos ramas al sur y este respectivamente, permitiendo el desarrollo de las discordancias sinsedimentarias.

La ausencia de rodados de las metavolcanitas que afloran en el cerro Negro y extremo norte de la sierra de Velasco, indica que este cerro y una buena parte del extremo de esta sierra, no formaban parte de los relieves positivos emisores de rodados.

La figura 9A es un bloque diagrama de las Cumbres de los Pozuelos en las inmediaciones de los cortes de la ruta nacional 60 y la línea de ferro- carril. Se puede apreciar el diseño divergente de las discordancias, cuando se mira hacia el ENE desde una posición cercana a la falla Velasco. El bloque diagrama fue construido sobre la base de un mapeo detallado de las discordancias en una extensión de $2 \mathrm{~km}$ en sentido este-oeste a ambos lados de los cortes de la ruta nacional 60 y la línea de ferrocarril. A medida que las discordancias convergen, el buzamiento general de las secuencias crece. Fuera de la figura 9, las discordancias vuelven a juntarse en las vecindades de la falla Aimogasta. Es evidente que los esfuerzos mayores ocurrieron en el tramo de la falla Uscamayo cercano a estas dos fallas, siendo la región intermedia a la ruta nacional 60 , el sector de máxima subsidencia.

En la figura 9B se muestra el sentido de desplazamiento de las tres fallas principales relacionadas con la deformación y generación de las discordancias sinsedimentarias de la Formación Las Cumbres.

El análisis de las fallas principales utilizando imágenes Landsat 7 muestra el desplazamiento sinistral de la falla Aimogasta con escaso rechazo vertical. Por su parte, la falla Velasco levanta el bloque que forma el extremo norte de la sierra homónima y tiene gran rechazo vertical, el que aumenta progresi-

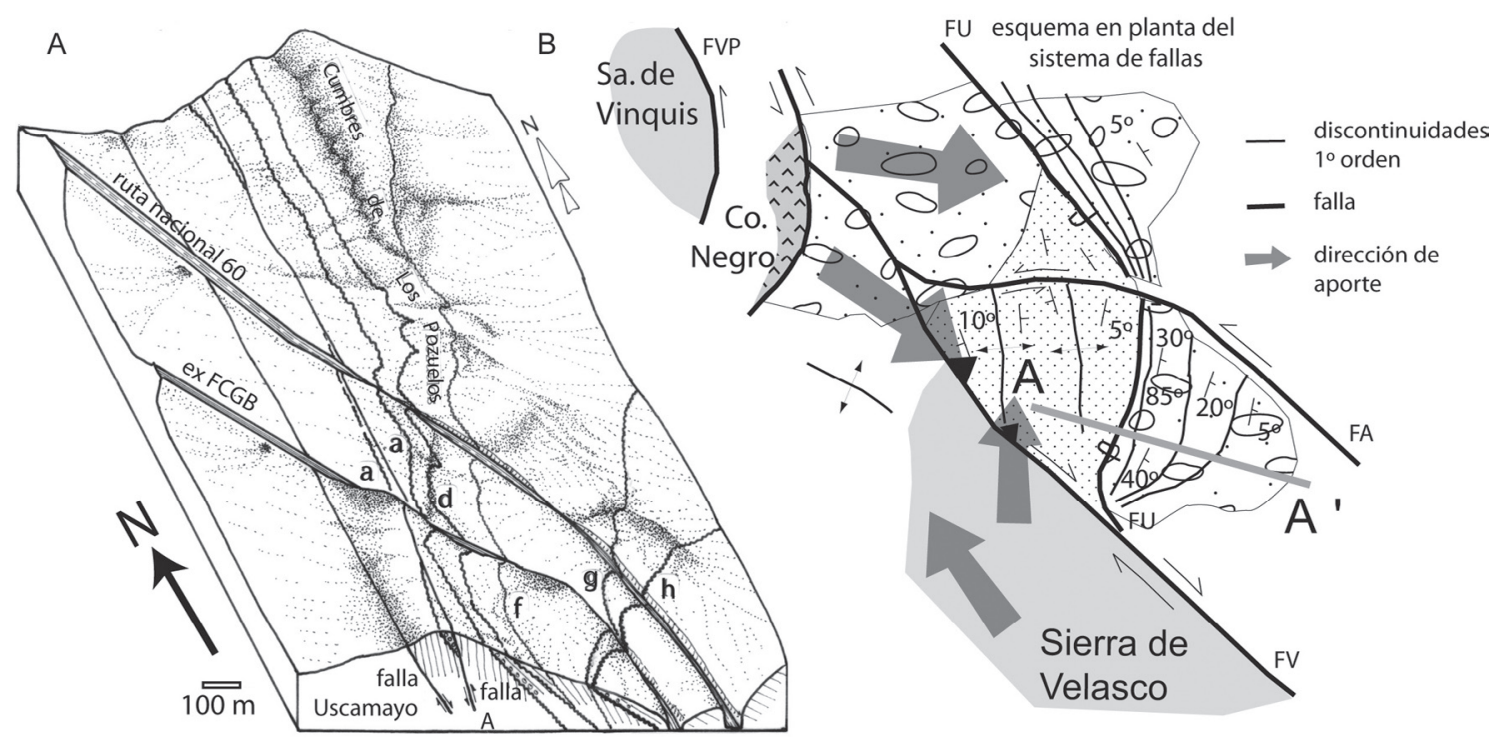

FIG. 9. Disconformidades visibles en las Cumbres de los Pozuelos. A. Bloque diagrama mostrando la exposición areal, extensiones y relaciones de las discontinuidades de $1^{\circ}$ orden $(\mathrm{a}, \mathrm{d}, \mathrm{h})$ y algunas de las discontinuidades de $2^{\circ}$ orden (f, g) y la manera en que son cortadas por la traza de la ruta nacional 60 y del ex FCGB; la falla A produce la repetición de la sucesión sedimentaria tal como se la representa en la figura 8 y se la interpreta en la figura 10; B. Mapa de las disconformidades, cambios de inclinación, sierras, estructuras principales y la orientación del corte A-A' representado en las figuras 8 y 10. FVP: Falla Vinquis-Paimán, FU: Falla Uscamayo, FA: Falla Aimogasta, FV: Falla Velasco. Las referencias de las rastras corresponden a la figura 1. 
vamente hacia el sur, además de un desplazamiento dextral. La inclinación del plano de falla es variable entre $60^{\circ}$ y $90^{\circ}$. En el trecho cercano al extremo norte de la sierra, se ve el basamento montado sobre la Formación Salicas con un ángulo de $17^{\circ}$. Esto puede haber contribuido al desplazamiento rotacional dextrógiro de esta última porción de la sierra en la etapa final de elevación y deformación del anillo de lomadas. Es evidente que el desplazamiento hacia el SE de los bloques constituidos por el cerro Negro y la sierra de Vinquis generó el empuje necesario para que la falla Uscamayo tenga un carácter transpresivo dextral.

Finalmente, la falla Uscamayo (Bossi et al., 1996) pone en contacto el sector superior de la Formación Las Cumbres con la parte baja de la Formación Salicas. La falla tiene un rumbo diagonal (NE-SO) respecto a las fallas mayores que presentan un rumbo NNO-SSE. La falla Uscamayo presenta un diseño sigmoidal asintótico hacia ambas fallas. Es una falla transpresiva de alto ángulo, que puede haberse iniciado como una falla inversa con buzamiento al SE, que ha propiciado una serie de etapas de fuerte empuje hacia el sur del bloque ubicado al norte de la falla, generando el basculamiento y la deformación de la Formación Las Cumbres en el tramo ubicado al sur de la misma. Mientras este bloque se hundía y cobijaba las capas deformadas de la Formación Las Cumbres, el bloque norte (pendiente) era sometido a fuerte erosión, estableciendo una superficie de pedimentación que eliminó todo resto de la Formación Las Cumbres llegando a suprimir gran parte de la Formación Salicas.

Cabe destacar que las imbricaciones en las cuatro secuencias que forman las lomadas de las Cumbres de los Pozuelos y las ubicadas en la rama norte-sur del anillo, al este del curso del río Colorado, indican una dirección de flujo que se hunde hacia abajo, en la dirección del manteo. Esto indica que los conglomerados fueron empujados y volcados hacia el sur y este respectivamente. El bloque colgante (ubicado en la región central del anillo) contiene actualmente depósitos de la sección inferior de la Formación Salicas, suavemente plegada con ejes de los pliegues subparalelos con la traza de la falla Uscamayo y diagonales con la orientación de las fallas y estructuras mayores. Este plegamiento está despegado del basamento en la misma superficie de no conformidad o algo más arriba, siguiendo secciones limosas y es producto de la deformación asociada al desplazamiento del bloque intermedio entre las fallas Aimogasta y Velasco, empujado hacia el sur por los ya mencionados núcleos de basamento emergido (Fig. 3). El rechazo estratigráfico acumulado en ambos labios de la falla Uscamayo es superior a $400 \mathrm{~m}$, un valor muy grande, considerando el espesor total de las unidades involucradas.

En tiempos recientes se advierte que ocurrió una inversión del relieve, quedando los conglomerados de la Formación Las Cumbres más altos que los afloramientos de la Formación Salicas, que aparecen topográficamente deprimidos. Este efecto puede relacionarse con erosión pluvial, fluvial y deflación, que atacaron selectivamente a la Formación Salicas, preservando en las lomadas los conglomerados de Las Cumbres que son más resistentes a tales procesos.

El pasaje entre las Formaciones Salicas y Las Cumbres en el sector norte del anillo de lomadas, denominado las Cumbres del Médano, es transicional y ambas unidades mantean suavemente hacia el norte sin que haya ningún tipo de discordancia. Este comportamiento contrasta con la situación particular verificada junto a la falla Uscamayo en las Cumbres de los Pozuelos. El caso que describimos muestra varias etapas de reactivación de la falla, con diferencias decrecientes de intensidad, generando una asociación de cuatro alounidades discordantes. Sólo en la alounidad II se observa una leve tendencia a la organización divergente de los planos de estratificación.

La figura 10 muestra una reconstrucción en sección longitudinal a las secuencias, considerando a cada una con espesor constante. Se puede observar que la alounidad I marca la etapa de mayor actividad de la falla, que fue concomitante con la de mayor aporte de materiales del área fuente al abanico aluvial y corresponde al clímax de la inversión tectónica en la región de las sierras Pampeanas de Tucumán y Catamarca (Bossi et al., 2001). La reconstrucción permite ver que la intensidad de los sucesivos eventos ocurridos posteriormente era cada vez menor y termina poco después del emplazamiento de la alounidad IV que participa con un espesor muy reducido.

Las alounidades I y II aparecen repetidas por una falla próxima a la falla Uscamayo. El trazado en profundidad de esta falla es de difícil predicción. La reconstrucción ubica una faja de sedimentitas de la alounidad I entre las dos fallas que se supone constituye el núcleo más deformado de la estructura. 


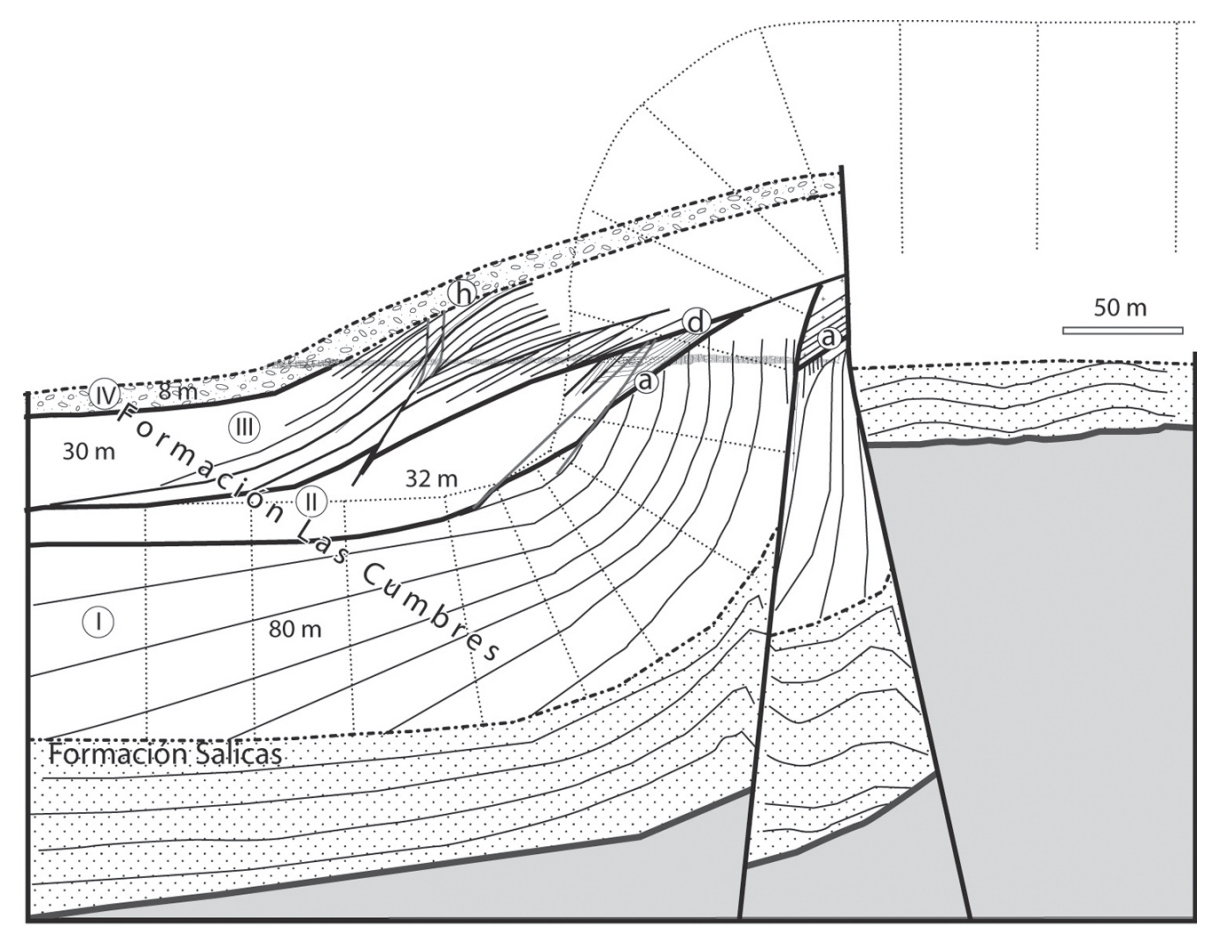

FIG. 10. Reconstrucción de la estructura profunda asociada al corte A-A' (figura 5) a lo largo del corte de la ruta 60.

Es posible que esta falla no afecte a las alounidades posteriores. Las fallas menores ubicadas en las alounidades II y III, son planas y de poco rechazo, aunque en el caso de la alounidad II han producido una importante rotación de los bloques de las facies $\mathrm{S}$ que son las menos competentes. Se puede inferir que estas fallas solamente actuaron sobre las alounidades I y II, pues se pudo observar que son cortadas por la discordancia de la base de la alounidad III.

\section{Paleocorrientes}

El análisis de paleocorrientes de la Formación Las Cumbres fue hecho mediante un muestreo regional, aleatorio no jerarquizado, donde se midieron direcciones de flujo en rodados imbricados, rodados máximos y composición de rodados. La figura 4 presenta los datos de paleocorrientes medidos a lo largo del perfil estratigráfico y la figura 8 los obtenidos en el corte de la ruta nacional 60 en las Cumbres de los Pozuelos. Las localidades correspondientes al resto de las mediciones se indican con las flechas de sus modas en los mapas temáticos (Fig. 11). En el gabinete se corrigió a la horizontal por inclinación secundaria con el programa Rockworks $2005 \AA$, usando rumbos y buzamientos medidos siguiendo la regla de la mano derecha. El procedimiento posterior de cálculo de la moda y otros estadísticos siguió el procedimiento de Gumbel et al. (1953), descrito con detalles de cálculo y las tablas estadísticas necesarias en Bossi (2001).

La comparación de los datos de paleocorrientes medidos en las Formaciones Salicas y Las Cumbres, permite reconocer ciertas diferencias entre las direcciones de flujo de ambas unidades. Sin embargo, esta conclusión debe considerarse preliminar, pues está basada únicamente en las mediciones realizadas a lo largo del perfil estratigráfico relevado desde la base de la Formación Salicas junto a la penillanura expuesta en el extremo norte de la sierra de Velasco y la superficie geomórfica que define el tope de las Cumbres del Médano.

El análisis de paleocorrientes de la Formación Las Cumbres, realizado en escala regional, muestra un sistema de dispersión de carácter complejo con fuentes ubicadas al norte, sur y este y un diseño de paleoflujos orientado principalmente hacia el este. La disposición de las medias armónicas de paleocorrientes muestra claramente el sentido general, 
casi lineal, del sistema de flujo con una ligera flexión alrededor de la sierra de Velasco.

El comportamiento del sistema de dispersión se analiza con detalle mediante la serie de mapas temáticos (Fig. 11) realizados con las modas de paleocorrientes por localidad, combinadas con los tamaños de rodados y abundancia relativa (\%) de las principales composiciones de los rodados, discriminadas en metavolcanitas, granitos rosados, metamorfitas, granitos grises, milonitas y volcanitas terciarias. El conjunto de mapas temáticos permitió no sólo definir la posición de las rocas madres involucradas sino también la relación entre el sistema de dispersión y los bloques de montaña circundantes. La distribución de rodados máximos es particularmente anómala en todos los mapas temáticos. La posición actual de las sierras se muestra en siluetas con trazo grueso. La posición probable de las sierras, en el momento de la sedimentación de la Formación Las Cumbres, compatible con el sistema de paleocorrientes, aparece con rastra plena.

El sistema de dispersión de las metavolcanitas (Fig. 11A) es de carácter local y está relacionado con un área fuente particular que se encuentra en el extremo norte del cerro Negro. La posición actual de esta elevación no se condice con este resultado. La sección occidental del área afectada por la fallas Vinquis-Paimán y cerro Negro, estaba ubicada más al norte, en el momento de la depositación de la Formación Las Cumbres, tal como lo sugiere la figura 11A.

La figura 11B presenta el comportamiento de los rodados metamórficos. Las rocas madres correspondientes están ubicadas en las sierras del sector norte de donde proviene el grueso de estos rodados. El sistema de drenaje puede considerarse compatible con la posición actual de las sierras, pero por razones de consistencia se ha respetado el diseño probable de las sierras en el momento de la depositación de la Formación Las Cumbres que surge de las consideraciones vertidas para el mapa temático previamente discutido (Fig. 11A).

La figura $11 \mathrm{C}$ ilustra sobre el comportamiento de los rodados máximos y abundancia relativa de los granitos rosados. Como puede observarse, estos granitos provienen principalmente de las sierras de Vinquis y Velasco con un aporte menor desde el oeste. Decrecen aguas abajo hasta las Cumbres de los Pozuelos donde aumentan de tamaño debido a procesos secundarios de retrabajado muy manifiestos en las bases de las alounidades II y III.

La figura 11D muestra la distribución de los rodados volcánicos que corresponden en gran parte a andesitas y dacitas grises y verdosas y, en menor escala, a basaltos negros. Estos rodados provienen de la destrucción de aparatos volcánicos activos durante el Mioceno Medio a Superior y aparecen dispersos en el basamento pampeano. Cuerpos volcánicos de naturaleza andesítica han sido mapeados tanto en la sierra de Vinquis y entre ésta y la sierra de Zapata (Socic, 1972; aunque por cuestiones de escala estos cuerpos volcánicos no pueden ser representados en la figura 11D) y también intruyendo rocas triásicas y pérmicas del borde precordillerano, ubicadas al oeste de las sierras de Paimán y Copacabana (fuera del área de estudio). El mapa de la figura 11D revela una proveniencia de ambos sectores, siempre con abundancias relativas bajas, debido a su menor participación en el área fuente.

El sistema de dispersión basado en los rodados de granitos grises (Fig. 11E) es similar al de los granitos rosados que por otra parte son rocas de mucha difusión en el área de estudio. Sin embargo, exhiben un esquema de proveniencia desde la sierra de Paimán y desde los sectores sur del cerro Negro y sierra de Vinquis en la posición probable que se plantea en el mapa (siguiendo los mapas temáticos anteriores). La disposición de la abundancia y tamaño de estos rodados y las modas de paleocorrientes, resultan inconsistentes con la posición actual de las sierras (siluetas grises de borde negro grueso), al igual que en las litologías previamente descritas.

La figura $11 \mathrm{~F}$ muestra la distribución de los rodados de milonitas y granitoides deformados que son por lo general angulosos y dominan por su abundancia el sector austral del área aflorante. Los tamaños máximos se encuentran asociados al borde oeste, pero la abundancia mayor proviene de las sierras de Paimán y el cerro La Punta. Se ha detectado también la presencia de rodados sobredimensionados en las localidades ubicadas más al oeste, cercanas a la traza del río Pituil. Estos rodados angulosos, de más de un metro de longitud máxima, se asocian a conglomerados de guijas y guijarros angulosos.

Todos estos conglomerados corresponden a facies de flujos mixtos acumulados en una bajada de distributarios cercana al borde distal de los abanicos aluviales de donde provienen. 

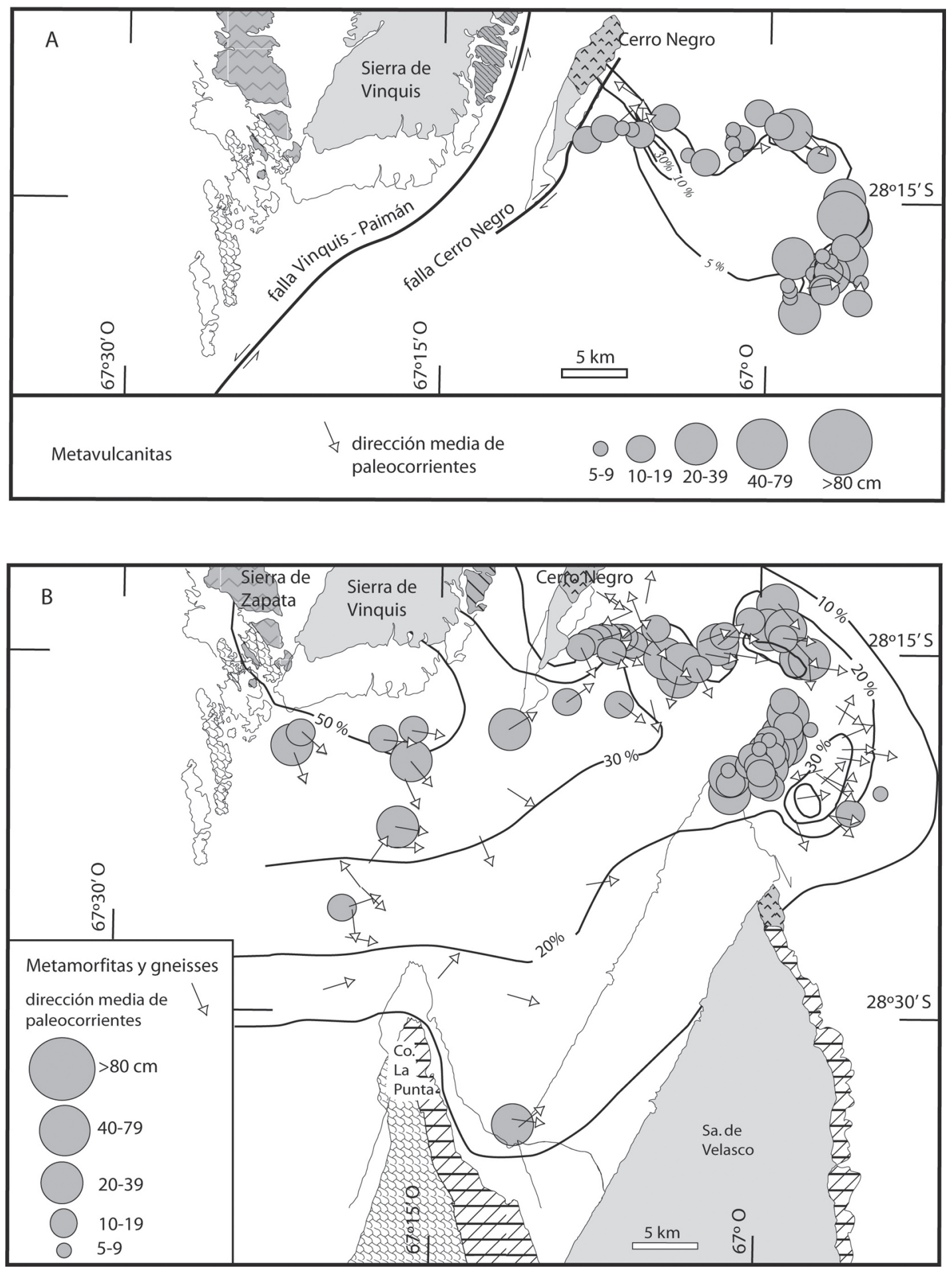

FIG. 11. (A-B). Distribución de rodados máximos y sus concentraciones discriminadas por litologías. Mapas temáticos de paleocorrientes (modas por localidad), rodados máximos y abundancia relativa (\%) de seis litologías conspicuas en los conglomerados de la Formación Las Cumbres. A. metavolcanitas; B. metamorfitas y gneises. Ver geología en figura 1. 

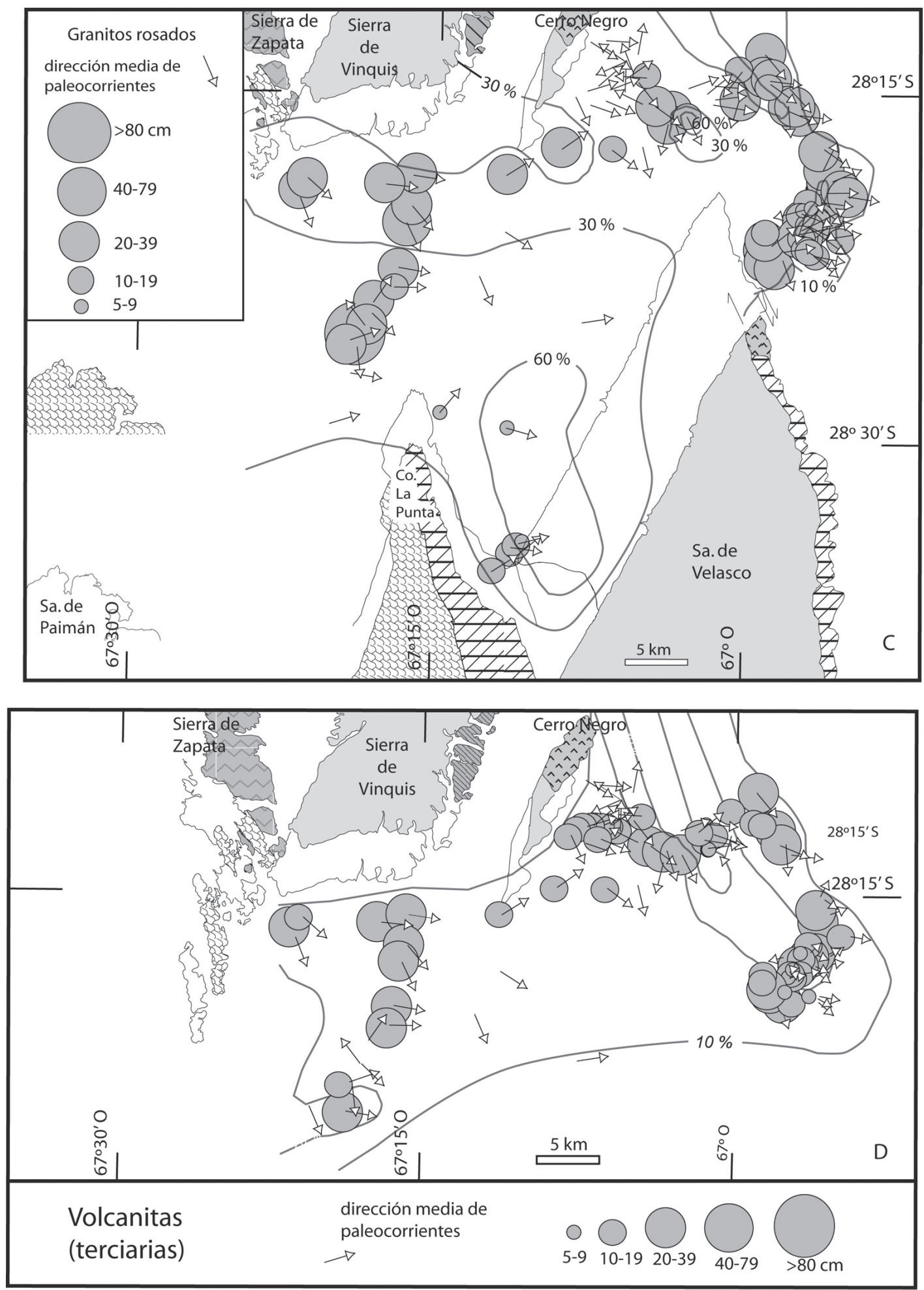

FIG. 11. (C-D). Distribución de rodados máximos y sus concentraciones discriminadas por litologías. Mapas temáticos de paleocorrientes (modas por localidad), rodados máximos y abundancia relativa (\%) de seis litologías conspicuas en los conglomerados de la Formación Las Cumbres; C. granitos rosados; D. rodados volcánicos. 

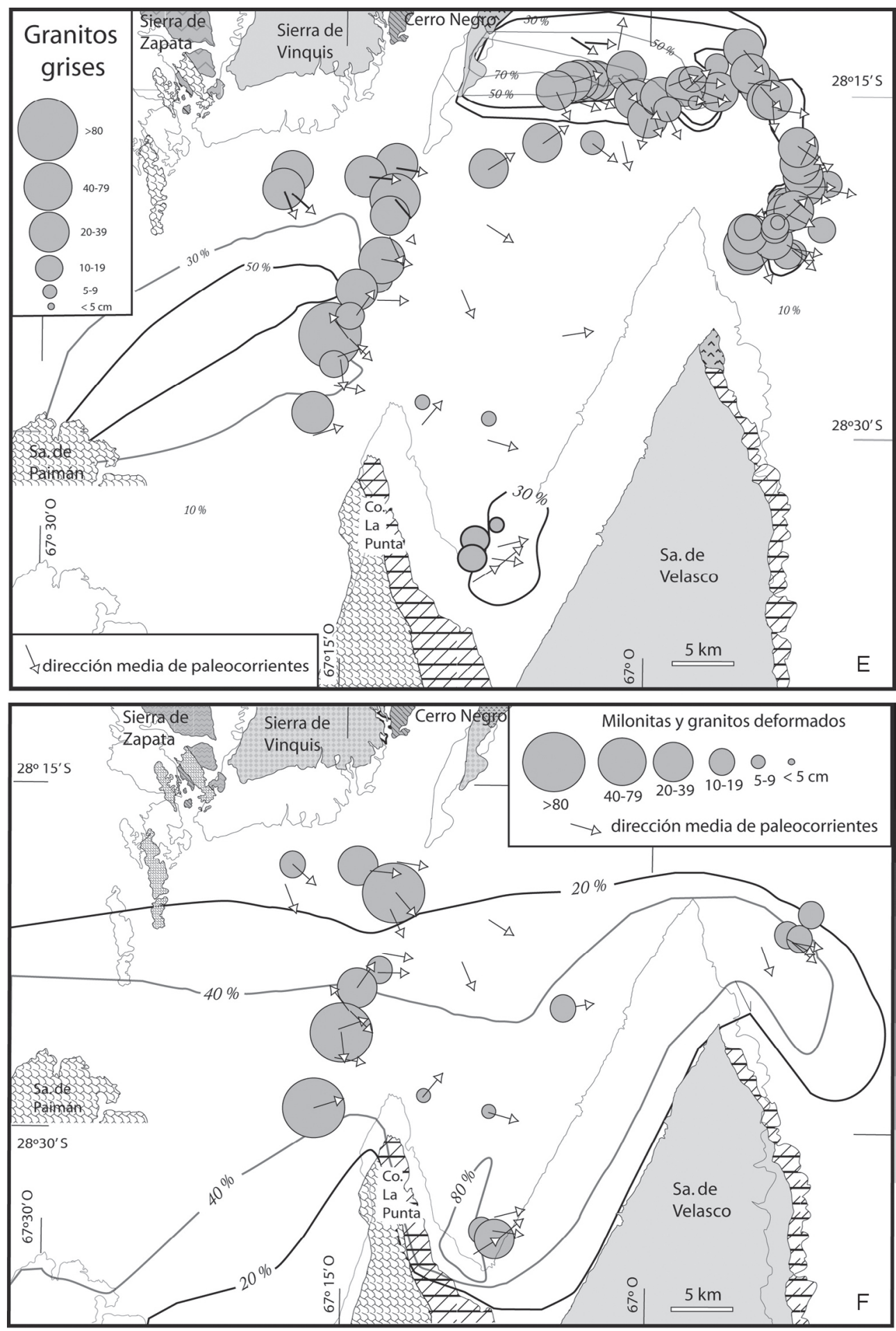

FIG. 11. (E-F). Distribución de rodados máximos y sus concentraciones discriminadas por litologías. Mapas temáticos de paleocorrientes (modas por localidad), rodados máximos y abundancia relativa (\%) de seis litologías conspicuas en los conglomerados de la Formación Las Cumbres. E. granitos grises; F. milonitas y granitoides deformados angulosos. Las siluetas de las sierras indican su posición actual, las sierras con la indicación de la litología (ver referencias en la figura 1) corresponde a la posición de las mismas mientras se producían los rodados de las distintas litologías. 
El análisis de las 85 localidades relevadas, expresadas mediante medias armónicas, queda sintetizado en la figura 12, donde se destaca la presencia de dos sistemas parcialmente solapados de dispersión: (a) de conglomerados redondeados provenientes de las sierras ubicadas en el sector norte, dominados por granitos rosados, grises, metamorfitas, metavolcanitas y volcanitas terciarias; y (b) conglomerados finos con rodados angulosos, dominados por milonitas y granitoides deformados provenientes de las sierras ubicadas en los bordes oeste y sur del área aflorante. Ambos sistemas convergen hacia el extremo este del área de afloramientos, perdiéndose en el vecino Bolsón de Pipanaco.

La observación de estos mapas permite inferir que la actual posición de las sierras es inconsistente con las paleocorrientes medidas y en algunos casos hasta con la disposición de los rodados máximos y abundancias relativas de los componentes considerados.

Los valores de paleocorrientes medidos en el corte de la ruta 60 sobre las Cumbres de los Pozuelos (Fig. 8), son coherentes con una dirección modal hacia el sur-sureste, excepto los medidos en las facies S de la alounidad II y comienzo de la alounidad III (Fig. 11). En ambas situaciones las modas dominantes son hacia el SE y en forma minoritaria hacia el este. Aunque tales valores no se apartan significativamente de la gran moda, indicarían que gran parte del extremo norte de la sierra de Velasco no había emergido como relieve positivo destacado y aún permanecía en el subsuelo de cuenca, o en su defecto se encontraba ubicado más al sur. Si la primera hipótesis fuese la correcta los rodados de metavolcanitas de la alounidad IV tendrían que haberse hecho presentes con una abundancia alta debido a que afloran en la punta de la sierra de Velasco. Tal no es el caso, de manera que se prefiere considerar como más adecuada la segunda hipótesis.

La evidencia composicional y de paleocorrientes, discutida más arriba, permite inferir que vastos sectores del basamento no se hallaban expuestos, en la posición que ocupan hoy en día, en los tiempos que se desarrolló la gran bajada de la Formación Las Cumbres.

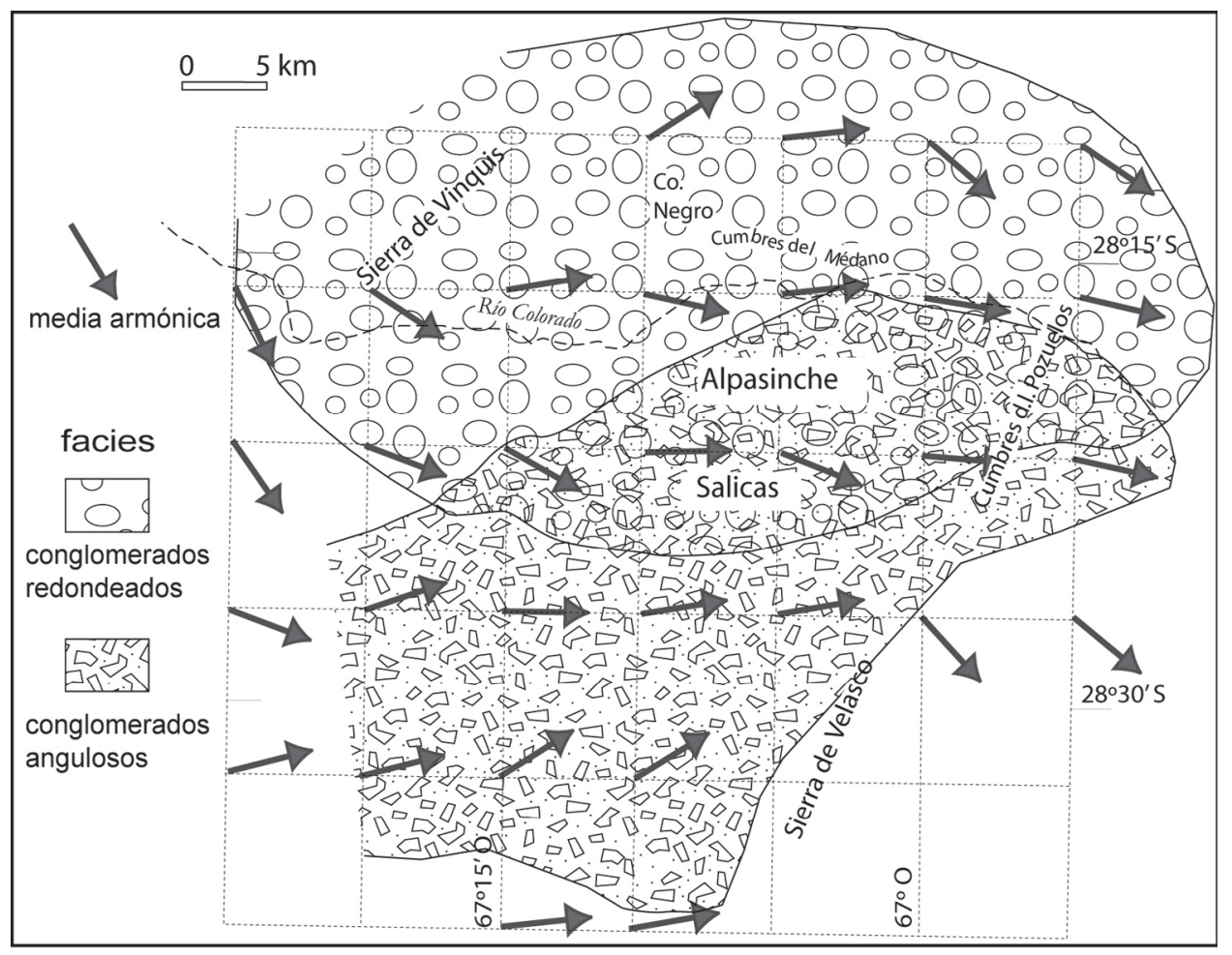

FIG. 12. Mapa esquemático de los dos sistemas de dispersión asociados a la Formación Las Cumbres y medias armónicas de las direcciones de paleocorrientes. 


\section{Conclusiones}

- La acumulación de la Formación Salicas, que implica relieves reducidos y áreas fuentes distantes, corresponde a la etapa previa a la inversión tectónica y levantamiento de las actuales Sierras Pampeanas circundantes (Vinquis, Zapata, cerro Negro y la sierra de Velasco).

- Con la inversión tectónica comienza el desplazamiento y levantamiento del conjunto serrano integrado por las sierras de Vinquis, Zapata y cerro Negro por el norte y la sierra de Paimán al oeste y las sierras de Velasco y la Punta al sur, que generaron una enorme bajada dirigida hacia el SE que penetró el borde occidental del gran bajo aledaño (Bolsón de Pipanaco) en una extensión en sentido oeste-este de $60 \mathrm{~km}$. El efecto combinado, del levantamiento y desplazamiento hacia el norte de los bloques de la sierra de Velasco y del cerro Negro y la sierra de Vinquis hacia el sur, contribuyó a la formación de la falla transversal y transpresiva Uscamayo y al desarrollo de las discordancias sinsedimentarias de las Cumbres de los Pozuelos en el labio hundido suroriental.

- El desplazamiento relativo de la Falla Uscamayo generó un espacio de acumulación de características extraordinarias al sur de esta última (Cumbres de los Pozuelos) en sucesivas etapas de deformación y hundimiento, separadas por etapas de alabeo de la superficie de acumulación seguidas por erosión y pedimentación en el labio elevado (occidental), lo que permitió el desarrollo de las discordancias angulares, cubiertas de gravas de rezago, que separan las cuatro alounidades que constituyen la sucesión aflorante en las Cumbres de los Pozuelos.

\section{Agradecimientos}

Los autores desean agradecer las sugerencias vertidas por los árbitros de este trabajo Dr. L.A. Spalletti, Dr. V.A. Ramos y Dr. J. Le Roux, cuyas observaciones permitieron mejorar la presentación.

\section{Referencias}

Blair, T.C. 1987. Hydrologic and tectonic controls on alluvial fan delta flood basin sedimentation, southwestern United States and their implication to the development of cyclic marginal fan and flood basin megasequences. In International Symposium on Fan Deltas. Geological Institute, Actas: 121-122. Bergen, Norway.
Blair, T.C.; McPherson, J.G. 1994. Alluvial fans and their natural distinction from rivers based on morphology, hydraulic processes, sedimentary processes and facies assemblages. Journal of Sedimentary Research A64 (3): 450-489.

Blair, T.C.; McPherson, J.G. 1999. Grain-size and textural classification of coarse sediments. Journal of Sedimentary Research 69 (1): 6-19.

Bodenbender, G. 1924. El Calchaqueño y los estratos de la Puna de Penck. Boletín de la Academia Nacional de Ciencias de Córdoba 27: 405-468.

Bossi, G.E. 2001. La distribución de densidad normal circular y sus aplicaciones en Geología. Acta Geológica Lilloana 18 (2): 311-324.

Bossi, G.E.; Villanueva García, A.; Sosa Gómez, J. 1989. Revisión de la magnetoestratigrafía del Neógeno del bolsón de Fiambalá (Prov. de Catamarca, Argentina). In Reunión sobre Geotransectas de América del Sur, Transecta No. 6, Actas: 146-150. Mar del Plata.

Bossi, G.E.; Muruaga, C.M.; Sanagua, J.G.; Hernando, A.; Ahumada, A.L. 1993. Geología y estratigrafía de la cuenca neógena de Santa María-Hualfín (Departamentos Santa María y Belén, Provincia de Catamarca). In Congreso Geológico Argentino, No. 12, Actas 2: 156-165. Mendoza.

Bossi, G.E.; Sanagua, J.G.; Georgieff, S.M.; Ibánez, L.M.; Muruaga, C.M.; Quiroga, G. 1996. Discordancias sinsedimentarias en los conglomerados de pie de monte en el extremo norte de la Sierra de Velasco (La Rioja, Argentina). In Reunión Argentina de Sedimentología, No. 5, 1: 123-128. Bahía Blanca.

Bossi, G.E.; Georgieff, S.M.; Gravriloff, I.J.C.; Ibáñez, L.M.; Muruaga, C.M. 2001. Cenozoic evolution of the intermontane Santa María Basin, Pampean Ranges, northwestern Argentina. Journal of South America Earth Sciences 14 (7): 725-734.

ComitéArgentino de Estratigrafía. 1992. Código Argentino de Estratigrafía. Asociación Geológica Argentina, Serie B (Didáctica y Complementaria) 20: 64 p. Buenos Aires.

Gani, M.R. 2004. From turbid to lucid: a direct form of approximation to gravity flows and their deposits. Sedimentary Record 2 (3): 4-8.

González Bonorino, F. 1972. Descripción Geológica de la Hoja 13c, Fiambalá, Provincia de Catamarca. Carta Geológico-Económica de la República Argentina. Boletín Dirección Nacional de Geología y Minería 127: 1-75.

Gumbel, E.J.; Greenwood, J.A.; Durand, D. 1953. The circular normal distribution, theory and tables. Journal American Statistical Association 48 (261): 131-152.

Middleton, G.V. 1965. Antidune cross-bedding in large flume. Journal of Sedimentary Petrology 35 (4): 922-927.

Mulé, P.; Powell, J.E.; Bossi, G.E. 1997. Notoungulados de la Formación Salicas (Mioceno), La Rioja, Argentina. Aspectos sedimentológicos y cronológicos. In 
Jornadas Argentinas de Paleontología de Vertebrados, No. 13, Acta de Resúmenes. La Rioja.

Muruaga, C.M. 1998. Estratigrafía y Sedimentología del Terciario Superior de la Sierra de Hualfín, entre las localidades de Villavil y San Fernando, Provincia de Catamarca. Tesis Doctoral (Inédito), Universidad Nacional de Tucumán, Facultad de Ciencias Naturales e Instituto M. Lillo: 270 p. Tucumán.

North American Comission of Stratigraphic Nomenclature. 1983. North American Stratigraphic Code. Bulletin of the American Association Petroleum Geologists 67 (5): 841-875.

Nullo, F. 1981. Descripción Geológica de la Hoja 15f, Huillapima, Provincia de Catamarca. Carta GeológicoEconómica de la República Argentina. Boletín de Secretaría de Estado de Minería 178: 1-62 p. Buenos Aires.

Riba Arderiu, O. 1989. Las discordancias sintectónicas como elementos de análisis de cuencas. In Sedimentología, Nuevas Tendencias (Arche,A.; editor). Consejo
Superior de Investigaciones Científicas 2: 489-522.

Sosic, M. 1972. Descripción Geológica de la Hoja 14d, Tinogasta, Provincias de Catamarca y La Rioja. Boletín Dirección Nacional de Geología y Minería 129: 1-56.

Sosa Gómez, J.; Bossi, G.E.; Villanueva García, A. 1993. Tectónica del Neógeno en el Bolsón de Fiambalá, Provincia de Catamarca. Zentralblatt Geologie und Paleontologie 1: 319-331.

Tauber, A.A. 2005. Mamíferos fósiles y edad de la Fm. Salicas (Mioceno tardío) de la Sierra de Velasco, La Rioja, Argentina. Ameghiniana 42 (2): 443-460.

Wells, S.; Harvey, A. 1987. Sedimentologic and geomorphic variations in storm generated alluvial fans, Howgills Fells, northwest England. Bulletin of the Geological Society of America 98 (2): 182-198.

Zielinski, T. 1982. Contemporary high-energy flows, theirs deposits and reference to the outwash depositional model. Pracel Naukowe Uniwersytetu Slakiego, NR 519, Geology 6: 98-110. 